\title{
Satellite NG2 Progenitor Cells Share Common Glutamatergic Inputs with Associated Interneurons in the Mouse Dentate Gyrus
}

\author{
Jean-Marie Mangin, ${ }^{1 *}$ Albrecht Kunze, ${ }^{1,2 *}$ Ramesh Chittajallu, ${ }^{1}$ and Vittorio Gallo ${ }^{1}$ \\ ${ }^{1}$ Center for Neuroscience Research, Children's National Medical Center, Washington, DC 20010, and 2Department of Neurology, Friedrich Schiller \\ University, D-07747 Jena, Germany
}

\begin{abstract}
Several studies have provided evidence that NG2-expressing $\left(\mathrm{NG}^{+}\right)$progenitor cells are anatomically associated to neurons in gray matter areas. By analyzing the spatial distribution of NG2 ${ }^{+}$cells in the hilus of the mouse dentate gyrus, we demonstrate that NG2 ${ }^{+}$cells are indeed closely associated to interneurons. To define whether this anatomical proximity reflected a specific physiological interaction, we performed patch-clamp recordings on hilar NG2 ${ }^{+}$cells and interneurons between 3 and 21 postnatal days. We first observed that hilar $\mathrm{NG}^{+}{ }^{+}$cells exhibit spontaneous glutamatergic EPSCs (sEPSCs) whose frequency and amplitude increase during the first 3 postnatal weeks. At the same time, the rise time and decay time of sEPSCs significantly decreased, suggesting that glutamatergic synapses in NG2 ${ }^{+}$ cells undergo a maturation process that is reminiscent of what has been reported in neurons during the same time period. We also observed that hilar interneurons and associated $\mathrm{NG}^{+}$cells are similarly integrated into the local network, receiving excitatory inputs from both granule cells and CA3 pyramidal neurons. By performing pair recordings, we found that bursts of activity induced by GABAergic antagonists were strongly synchronized between both cell types and that the amplitude of these bursts was positively correlated. Finally, by applying carbachol to increase EPSC activity, we observed that closely apposed cells were more likely to exhibit synchronized EPSCs than cells separated by $>200 \mu \mathrm{m}$. The finding that $\mathrm{NG}^{+}$cells are sensing patterns of activity arising in closely associated neurons suggests that $\mathrm{NG}^{+}{ }^{+}$cell function is finely regulated by the local network.
\end{abstract}

Key words: neural progenitor cells; dentate gyrus; synaptic transmission; glutamate receptors; synchrony; oligodendrocyte; oligodendroglia

\section{Introduction}

Glutamatergic synapses have been reported on both gray and white matter NG2-expressing progenitor cells $\left(\mathrm{NG}^{+}\right.$cells) (Bergles et al., 2000; Lin et al., 2005; Kukley et al., 2007; Ziskin et al., 2007), but their functional significance remains elusive. Sustained activation of AMPA receptors (AMPARs) has been shown to decrease $\mathrm{NG}_{2}{ }^{+}$cell proliferation in vitro and prevent their differentiation into mature oligodendrocytes (Gallo et al., 1996). Endogenous glutamate levels are sufficient to inhibit proliferation and lineage progression of $\mathrm{NG}^{+}$cells in cerebellar slice cultures in 1-week-old mice (Yuan et al., 1998). However, the fact that white matter $\mathrm{NG}_{2}{ }^{+}$cells are still able to differentiate into

Received March 29, 2008; revised May 21, 2008; accepted June 6, 2008.

This work was supported by National Institutes of Health (NIH) Grants R01NS045702 (V.G.) and R21NS050463 (V.G.), Citizens United for Research on Epilepsy (V.G.), and NIH Intellectual and Developmental Disabilities Research Center Grant P30HD40677. A.K. was supported by an Interdisziplinäres Zentrum für Klinische Forschung Jena Fellowship (TP 1.7). We thank Dr. Dwight Bergles for discussion. We thank Dr. Tarik Haydar for assistance and training in the use of the Zeiss LSM-510 confocal microscope. We thank Dr. Robert McCarter, Dr. Ed Zhang, and Jianping He for their help with the simulation and distance measurement between $N G 2{ }^{+}$cells and neurons.

*J.-M.M. and A.K. contributed equally to this work.

This article is freely available online through the $J$ Neurosci Open Choice option.

Correspondence should be addressed to Vittorio Gallo, Center for Neuroscience Research, Children's Research Institute, Children's National Medical Center, Washington, DC 20010. E-mail: vgallo@enmcresearch.org. DOI:10.1523/JNEUROSCI.1355-08.2008

Copyright $\odot 2008$ Society for Neuroscience $\quad$ 0270-6474/08/287610-14\$15.00/0 oligodendrocytes while receiving glutamatergic contacts (Kukley et al., 2007; Ziskin et al., 2007) suggests that the physiological function of these synapses is probably more complex and diverse than a mere proliferation/differentiation switch. To address the potential function(s) of these synapses, it is thus important to determine the extent to which $\mathrm{NG}^{+}{ }^{+}$progenitor cells are functionally integrated into their local network.

In the cerebral cortex and hippocampus, $\mathrm{NG}^{+}{ }^{+}$cells are frequently found closely apposed to neuronal cell bodies and dendrites (Butt et al., 2005; Dayer et al., 2005; Lin et al., 2005). Although the extent of this relationship has not been clearly quantified, such anatomical proximity could reflect a specific physiological interaction between $\mathrm{NG}^{+}$cells and associated neurons. The purpose of the present study was to first demonstrate by a quantitative method the anatomical association of NG2 cells to neurons and then determine its functional significance. In particular, we investigated the relationship existing between hippocampal GABAergic interneurons and local NG2 ${ }^{+}$ cells (Belachew et al., 2003; Aguirre et al., 2004). To simultaneously identify $\mathrm{NG}_{2}{ }^{+}$progenitor cells and GABAergic interneurons in hippocampal slices, we used the $2^{\prime}, 3^{\prime}$-cyclic nucleotide $3^{\prime}$-phosphodiesterase-enhanced green fluorescent protein (CNP-EGFP) transgenic mouse strain previously developed in our laboratory (Yuan et al., 1998; Belachew et al., 2002). In this 
mouse, $\mathrm{NG} 2{ }^{+}$cells can be readily identified based on their higher levels of EGFP fluorescence (Chittajallu et al., 2004, 2005), their unique stellate morphology, and their electrophysiological membrane properties (Chittajallu et al., 2004). Conversely, in the same mouse strain, a subpopulation of interneurons express lower levels of EGFP and all the electrophysiological features typical of GABAergic interneurons (Belachew et al., 2003; Aguirre et al., 2004; Chittajallu et al., 2007). Therefore, this transgenic mouse strain enabled us to identify NG2 ${ }^{+}$progenitors and GABAergic interneurons, and to perform simultaneous electrophysiological recordings from these cells in the hilus of the dentate gyrus.

In the present study, we demonstrate that hilar NG2 ${ }^{+}$cells are closer to interneurons than expected by random distribution and that both cell types receive inputs from the same populations of excitatory neurons. More importantly, we provide evidence that the anatomical proximity of $\mathrm{NG}_{2}{ }^{+}$cells to interneurons renders them more likely to share inputs from the same presynaptic neurons.

\section{Materials and Methods \\ Materials}

The generation of the CNP-EGFP mouse used throughout this study has been described previously (Yuan et al., 2002). Two separate CNP-EGFP transgenic lines were used ( $\mathrm{C} 1$ and $\mathrm{D} 1)$, and data were pooled, because no differences were noted between the two. Animal procedures complied with guidelines of the National Institutes of Health and Children's Research Institute. All chemical reagents and drugs were from SigmaAldrich, unless otherwise stated; CNQX, lidocaine $N$-ethyl chloride (QX$314)$, gabazine (SR 95531), and $\left(2 S, 2^{\prime} R, 3^{\prime} R\right)-2-\left(2^{\prime}, 3^{\prime}\right.$-dicarboxycyclopropyl)glycine (DCG-IV) were from Tocris Bioscience; latrotoxin was from Alomone Labs. Primary antibodies used in the study and their working dilutions are as follows: anti-NG2 (rabbit; 1:500), anti-NeuN (mouse; 1:1000), anti-GAD65/67 (rabbit; 1:1000), and anti-somatostatin (rabbit; 1:200) (all from Millipore Bioscience Research Reagents). All secondary antibodies were from Jackson ImmunoResearch Laboratories and were used at a dilution of 1:200.

\section{Electrophysiology}

Slice preparation. CNP-EGFP mice from postnatal day 3 (P3) to P21 were anesthetized with isoflurane and decapitated, and their brains were removed. Brain hemispheres were rapidly dissected on ice and cut into $300-\mu$ m-thick horizontal sections on a Leica VT1000S vibratome, and then placed in an ice-cold oxygenated solution consisting of the following (in mM): $87 \mathrm{NaCl}, 2.5 \mathrm{KCl}, 1.25 \mathrm{NaH}_{2} \mathrm{PO}_{4}, 7 \mathrm{MgCl}_{2}, 0.5 \mathrm{CaCl}_{2}, 25$ $\mathrm{NaHCO}_{3}, 25$ glucose, 75 sucrose, $347 \mathrm{mOsm}$ at $\mathrm{pH}$ 7.4. Slices were stored in the same solution at $35^{\circ} \mathrm{C}$ for $30 \mathrm{~min}$, and then transferred into artificial CSF (ACSF) of the following composition (in mM): $124 \mathrm{NaCl}, 3 \mathrm{KCl}$, $2.5 \mathrm{CaCl}_{2}, 1.3 \mathrm{MgSO}_{4}, 26 \mathrm{NaHCO}_{3}, 1.25 \mathrm{NaHPO}_{4}, 15$ glucose, saturated with $95 \% \mathrm{O}_{2} / 5 \% \mathrm{CO}_{2}$ at room temperature $\left(20-25^{\circ} \mathrm{C}\right)$.

Patch-clamp recordings. Slices were transferred to a recording chamber and perfused with ACSF at a rate of $1-2 \mathrm{ml} \cdot \mathrm{s}^{-1}$. EGFP ${ }^{+}$cells were identified as described previously (Chittajallu et al., 2004, 2007). The present study targeted faint EGFP ${ }^{+}$interneurons and associated ("satellite") bright $\mathrm{EGFP}^{+} \mathrm{NG}^{+}$cells in the hilus of the dentate gyrus (see Fig. 1). Patch electrodes had resistances between 3 and $6 \mathrm{M} \Omega$ when usually filled with an intracellular solution of the following composition (in mM): $130 \mathrm{~K}$-gluconate, $10 \mathrm{NaCl}, 2 \mathrm{Mg}$-ATP, $0.3 \mathrm{Na}$-GTP, 10 HEPES, 0.6 EGTA, and biocytin $(5 \mathrm{mg} / \mathrm{ml})$, solution adjusted to $\mathrm{pH}$ 7.2, $275 \mathrm{mOsm}$ (junction potential, $13 \mathrm{mV}$ ). Specific experiments in voltage-clamp mode (see Fig. 8; supplemental Figs. 4 and 6, available at www. jneurosci.org as supplemental material) used an intracellular solution comprised of the following (in mM): $135 \mathrm{CsMeSO}_{3}, 8 \mathrm{NaCl}, 4 \mathrm{Mg}$-ATP, 0.3 Na-GTP, 0.6 EGTA, 10 HEPES, 5 QX-314, $5 \mathrm{mg} / \mathrm{ml}$ biocytin, $\mathrm{pH}$ adjusted to 7.3 with $\mathrm{CsOH}$ (junction potential, $14 \mathrm{mV}$ ). In the experiments analyzing glutamatergic activity synchronization during carbachol-induced theta oscillations (see Fig. 7), we used a specific internal solution containing the following (in mM): $130 \mathrm{CsMeSO}_{3}, 1 \mathrm{NaCl}, 4$ Mg-ATP, 0.4 Na-GTP, 10 EGTA, 10 HEPES, 5 QX-314-Cl, 5 mg/ml biocytin, $\mathrm{pH}$ adjusted to 7.3 with $\mathrm{CsOH}$ (junction potential, $14 \mathrm{mV}$ ). This solution allows discrimination of excitatory and inhibitory activity, giving far reversal potentials for EPSCs $(0 \mathrm{mV})$ and IPSCs $(-80 \mathrm{mV})$. By recording the cells at $-60 /-80 \mathrm{mV}$, EPSCs appeared as inward currents, whereas IPSCs are barely detectable or undetectable. The same internal solution was used to record GABAergic activity in satellite $\mathrm{NG}^{+}$cells $\left(\mathrm{sNG}^{+}\right.$cells) $\left(V_{\mathrm{h}}=0 \mathrm{mV}\right)$ (see Fig. 5). Whole-cell recordings were obtained using a Multiclamp 700B or an Axopatch 200B amplifier (both from Molecular Devices) and recordings were monitored via a PC running pClamp 9.2 (Molecular Devices). Field potential recordings were obtained using a glass electrode (tip resistance $\approx 0.5 \mathrm{M} \Omega$ ) filled with ACSF and connected to a Multiclamp 700B amplifier. Each of the different drugs was applied via the bath solution. Off-line analysis was performed using Clampfit 9.2 (Molecular Devices) and Mini Analysis (Synaptosoft). In all experiments, data were filtered at $10 \mathrm{kHz}$ during capacitance compensation and $5 \mathrm{kHz}$ during subsequent data recording. The traces were digitized at $10 \mathrm{kHz}$. All voltage measurements and steps were corrected for a junction potential offset.

Stimulation of neuronal fibers. The granule cell layer (GCL) and CA3 region of the hippocampal slices were stimulated with small bipolar electrodes (FHC) or, alternatively, with ACSF-filled, low-resistance $(<1$ $\mathrm{M} \Omega$ ), silver-painted electrodes to optimize the PSC recordings. Pulse sequences were generated using pClamp 9.2 (Molecular Devices) and applied with a constant current stimulus isolator (DS3; Digitimer). The stimuli used to elicit evoked EPSC varied between 10 and $500 \mu \mathrm{A}$ in intensity and were $100 \mu \mathrm{s}$ in duration. When stimulating the GCL, we usually used an isolated dentate gyrus slice to prevent activity from CA3 recurrent collaterals. In this, the dentate gyrus (hilus, GCL, and molecular layer) was dissected out from the hippocampal slice. Otherwise, we used whole hippocampal slices in which the whole hippocampus (dentate gyrus, CA3, CA2, CA1) was kept intact. The cells were usually voltage clamped at $-80 \mathrm{mV}$ (bright $\mathrm{EGFP}^{+}$cells) or $-60 \mathrm{mV}$ (interneurons). Before whole-cell recording, whole-cell capacitances and series resistances were compensated. Uncompensated series resistance values ranged from 6 to 19 $\mathrm{M} \Omega$, and average series resistances did not differ significantly between comparison cell groups ( $p>0.05$, Mann-Whitney $U$ test).

\section{Immunocytochemistry and confocal microscopy}

Single biocytin-filled, recorded EGFP ${ }^{+}$cells were visualized and underwent subsequent immunocytochemical characterization with anti-NG2, as described previously (Chittajallu et al., 2004). For immunocytochemistry in tissue sections, P14 CNP-EGFP mice were anesthetized with isoflurane and intracardially perfused with fixative (4\% paraformaldehyde), and their brains were removed. Coronal tissue sections (30-40 $\mu \mathrm{m})$ were prepared using a cryostat (Microm) and immunostained as described previously (Belachew et al., 2003). Images were acquired using a Carl Zeiss LSM 510 (Carl Zeiss). For all images, $z$-sections and $z$-steps ranged between 2 and $3 \mu \mathrm{m}$, respectively. Images were subsequently processed using LSM Image Examiner (Carl Zeiss), NIH ImageJ, or Adobe Photoshop/Illustrator (Adobe Systems).

To measure distances between NG2 ${ }^{+}$cell and the closest neuron, we analyzed two to three sections obtained at the same rostrocaudal level in each animal (three animals). For each section, a $z$-stack of $200 \times 200 \times$ $50 \mu \mathrm{m}$ was analyzed ( $z$-step, $2 \mu \mathrm{m}$ ). We manually pointed the center of each hilar $\mathrm{NG}_{2}^{+} \mathrm{EGFP}^{+}$cell, $\mathrm{NeuN}^{+} \mathrm{CNP}-\mathrm{EGFP}^{+}$neuron, and NeuN ${ }^{+}$CNP-EGFP-negative neuron to obtain the coordinate of each cell (Cell-counter plugin in the ImageJ software). We measured the total volume analyzed and counted the number of $4^{\prime}, 6^{\prime}$-diamidino-2phenylindole-positive $\left(\mathrm{DAPI}^{+}\right)$nuclei in this volume, to calculate the average density of each cell type and its relative frequency (see Fig. $1 \mathrm{~L}$ ). In hilar neurons, the nucleus, identified by NeuN immunostaining, was usually located at the center of the soma. Therefore, in neurons, nuclear and somatic center were considered equivalent. NG2 cells can display a more irregular morphology (see Fig. 1I) and their nucleus is not consistently found at the center of the soma. Because we were interested in measuring the relative proximity between somas of NG2 cells and neurons, we identified the center of each NG2 cell soma based on EGFP fluorescence rather than nuclear counterstaining. A large percentage of NG2 cells display a round or oblong-shaped soma (see Fig. $1 G$ ) in which 
the center is easily determined (see Fig. $1 G$, filled circles). In the few cells exhibiting more complex shape (as in Fig. 1I), the center was identified based on its minimal distance from the perimeter of the soma (see Fig. 1 I, filled circle).

The random distribution was obtained by generating virtual cells with random $X-Y-Z$ coordinates in a $200 \times 200 \times 50 \mu \mathrm{m}$ space. The density of virtual cells in this space was equal to the average density measured from all analyzed $z$-sections. The three-dimensional coordinates of each cell were exported to Excel (Microsoft), and the euclidian distance between each NG2 ${ }^{+}$cell and each neuron in the experimental or simulated $z$-stack was calculated by using a custom macro. Only the shortest distance calculated (distance to the closest neuron) was kept for each observed or virtually generated $\mathrm{NG}^{+}$cell to construct the observed and expected cumulative distribution shown in Figure $1 \mathrm{M}$.

\section{Statistical analysis}

Most of the statistical analysis was performed with the Mann-Whitney $U$ test, as mentioned in the text. The cumulative probability distribution of observed distance between $\mathrm{NG}^{+}$cells and the closest neurons were compared with the expected random distribution by using a Kolmogorov-Smirnov test. Coefficient of correlation between parameters was calculated using Pearson's product-moment correlation test.

\section{Results \\ $\mathrm{NG}_{2}{ }^{+}$cells tend to be associated with interneurons in the hilus of the dentate gyrus}

In brain tissue sections of CNP-EGFP mice, $\mathrm{NG} 2{ }^{+}$progenitors can easily be identified in the dentate gyrus based on their higher EGFP expression levels and stellate morphology (Fig. 1A-C) (Bergles et al., 2000). Indeed, virtually all the strongly positive EGFP-expressing cells were also stained for the proteoglycan NG2 during the postnatal (P3-P21) time window of our study. In the dentate gyrus of 14-d-old animals, we observed far less $\mathrm{NG}^{+}{ }^{+} \mathrm{EGFP}^{+}$cells located in the granule cell layer than in the hilus or the molecular layer (Fig. $1 A-C$ ), suggesting that $\mathrm{NG}_{2}{ }^{+}$ cells are more frequently associated with hilar interneurons than granule cells. Consistent with this hypothesis, $\mathrm{NG}^{+}{ }^{+} \mathrm{EGFP}^{+}$cell bodies and processes were frequently found in close apposition to neuronal dendrites and cell bodies of hilar neurons (Fig. 1D-G). To determine whether this distribution reflected a preferential cellular association between hilar $\mathrm{NG}^{+}$cells and neurons, we compared the spatial distribution of $\mathrm{NG}_{2}{ }^{+}$cells and neurons in the hilus with a random distribution of cells at the same density. First, we measured the average density of $\mathrm{NG} 2{ }^{+}$cells $(24.7 \pm 3.1$ cell per $10^{6} \mu \mathrm{m}^{3}$; three brains; $n=521$ cells) and neurons $(47.8 \pm$ 3.7; three brains; $n=1008$ cells) (Fig. $1 L$ ). In the hilus, the average distance of an $\mathrm{NG}^{+}$cell to its closest neuron was $14.9 \pm 6.7$ $\mu \mathrm{m}$ (average $\pm \mathrm{SD} ; n=295$ cells). The distribution of these distances differed significantly (Kolmogorov-Smirnov test, $D=$ $0.21 ; p<0.001)$ from a random distribution $(17.4 \pm 7.2 \mu \mathrm{m}$; distribution based on $n=5000$ simulated cells) (Fig. $1 M$ ).

In the hilus, a fraction of the neurons in contact with $\mathrm{NG}^{+}$ cells expressed low levels of EGFP (Fig. 1G, white arrow), a property restricted to a subpopulation of somatostatin-positive (70\%) (supplemental Fig. 1, available at www.jneurosci.org as supplemental material) and parvalbumin-positive (30\%) GABAergic interneurons in the mouse hilus [quantification obtained from Aguirre et al. (2004)]. Accordingly, all $\mathrm{EGFP}^{+} \mathrm{NeuN}^{+}$neurons coexpressed glutamic acid decarboxylase (GAD65/67) (Fig. $1 \mathrm{H}-$ $K)$. However, hilar $\mathrm{NG}^{+}$cells appeared as likely to be close to $\mathrm{CNP} \mathrm{EGFP}^{+}$interneurons as to other hilar neurons, likely to include hilar mossy cells. Indeed, the proportion of $\mathrm{NG}^{+}$cells whose closest neurons were either CNP-EGFP ${ }^{+}(41 \% ; n=121$ cells) or CNP-EGFP-negative ( $59 \% ; n=174$ cells) was similar to the relative frequency of each class of neurons in the hilus (43 and
$57 \%$, respectively). Moreover, the average NG2 ${ }^{+}$cell-neuron distances were similar for both $\mathrm{EGFP}^{+}$and EGFP-negative neurons $(14.8 \pm 6.8$ and $15.0 \pm 6.7 \mu \mathrm{m}$, respectively). Therefore, analysis of CNP-EGFP ${ }^{+}$GABAergic interneurons and their associated $\mathrm{NG}^{+}$cells is likely to unravel specific physiological interactions between these cells types that could be generalized to all hilar neurons. Hereafter, we will refer to $\mathrm{NG}^{+}{ }^{+}$cells directly apposed to CNP-EGFP ${ }^{+}$interneurons as satellite $\mathrm{NG}^{+}{ }^{+}$cells (sNG2 ${ }^{+}$cells).

\section{$\mathrm{sNG} 2^{+}$cells receive functional glutamatergic inputs}

Previous studies have shown that $\mathrm{sNG} 2^{+}$glial cells can be contacted by small, but fully functional glutamatergic synaptic terminals in both gray matter (for a recent review, see Paukert and Bergles, 2006) and white matter (Kukley et al., 2007; Ziskin et al., 2007). Thus, we first investigated the presence of spontaneous glutamatergic EPSCs (sEPSCs) in $\mathrm{sNG} 2^{+}$cells by performing whole-cell patch-clamp recordings in the presence of a $\mathrm{GABA}_{\mathrm{A}}$ receptor $\left(\mathrm{GABA}_{\mathrm{A}} \mathrm{R}\right)$ antagonist (picrotoxin; $100 \mu \mathrm{M}$ ) between 9 and 13 postnatal days. The phenotype of the recorded cells was confirmed by their characteristic current-voltage $(I-V)$ profile (Fig. 2A,B), their hyperpolarized resting membrane potential $(-86 \pm 4 \mathrm{mV} ; n=20)$, and by post hoc immunolabeling for the proteoglycan NG2 (Fig. $2 C)(n=24)$. sEPSPs (current-clamp mode) and/or currents (sEPSCs) (voltage-clamp mode) were clearly observed in $70 \%$ of recorded sNG2 ${ }^{+}$cells $(n=30$ of 43 ) (Fig. 2D). On average, sEPSPs exhibited a small amplitude of $0.9 \pm 0.2 \mathrm{mV}(\mathrm{SEM})$, with a rapid rise time $\left(\mathrm{Rt}_{20-90 \%}=0.5 \pm 0.2\right.$ $\mathrm{ms})$ and decay time constants $(3.1 \pm 0.6 \mathrm{~ms} ; n=5)$ (Fig. $2 E)$. In voltage-clamp mode, the average amplitude of sEPSCs was $-16.6 \pm 3.5 \mathrm{pA}$ with a rapid rise time and decay time of $0.28 \pm$ 0.04 and $1.20 \pm 0.11 \mathrm{~ms}$, respectively $(n=14)$ (Fig. $2 E$ ). However, in cells exhibiting such sEPSCs, the average frequency remained very low $(0.16 \pm 0.04 \mathrm{~Hz} ; n=14)$, compared with that measured in $\mathrm{EGFP}^{+}$GABAergic interneurons $(5.6 \pm 2.4 \mathrm{~Hz}$; $n=20)$.

In sNG2 ${ }^{+}$cells, bath application of cyclothiazide (CTZ) $(100$ $\mu \mathrm{M})$, which specifically blocks desensitization in AMPA receptors, increased the average amplitude of sEPSCs by $45 \pm 9 \%$ and drastically slowed their decay time by $172 \pm 20 \%(n=8)$ (Fig. $2 F)$. The application of CTZ also induced a doubling of sEPSC frequency, either because of a better detection of small sEPSCs and/or to an increase in overall network activity. Interestingly, $\mathrm{sNG}_{2}{ }^{+}$cells exhibiting spontaneous activity had a significantly lower membrane resistance and higher membrane capacitance $\left(R_{\mathrm{m}}=285 \pm 232 \mathrm{M} \Omega ; C_{\mathrm{m}}=32 \pm 9 \mathrm{pF} ; n=30\right)$ compared with nonsynaptically connected NG2 ${ }^{+}$cells $\left(R_{\mathrm{m}}=1100 \pm 705 \mathrm{M} \Omega\right.$; $C_{\mathrm{m}}=16 \pm 3 \mathrm{pF} ; n=13$ ) (Fig. $2 G$ ) (Mann-Whitney $U$ test). Because such a difference could reflect either the existence of two distinct population of $\mathrm{sNG} 2{ }^{+}$cells or an ongoing maturation process, we analyzed synaptic integration of $s \mathrm{NG} 2{ }^{+}$cells during postnatal development on a broader timescale.

\section{Hilar $\mathrm{sNG} 2{ }^{+}$cells are progressively integrated into the network during postnatal development and their inputs exhibit functional maturation}

To determine whether synaptic integration of sNG2 ${ }^{+}$cells is developmentally regulated, we recorded hippocampal sNG2 ${ }^{+}$cells from 3 to 20 postnatal days. During this period, the fraction of cells exhibiting sEPSC increased from 53\% (P3-P6; $n=9$ of 17) to $90 \%(\mathrm{P} 14-\mathrm{P} 20 ; n=9$ of 10$)$ and was correlated with a significant decrease in the average membrane resistance from $2085 \pm$ $582 \mathrm{M} \Omega(\mathrm{P} 3-\mathrm{P} 6)$ to $274 \pm 258 \mathrm{M} \Omega(\mathrm{P} 14-\mathrm{P} 20)(p<0.0001$, 

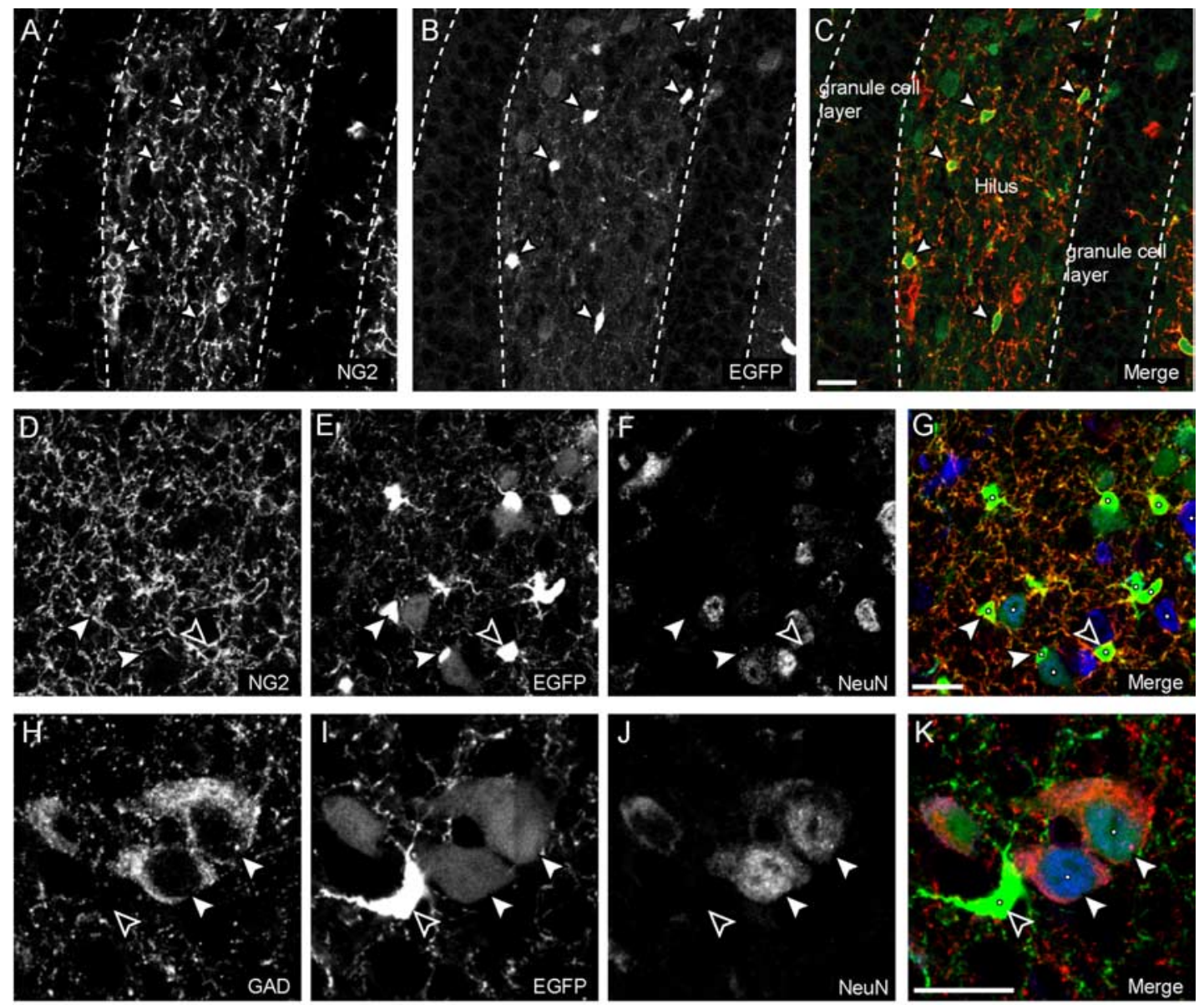

$\mathrm{L}$

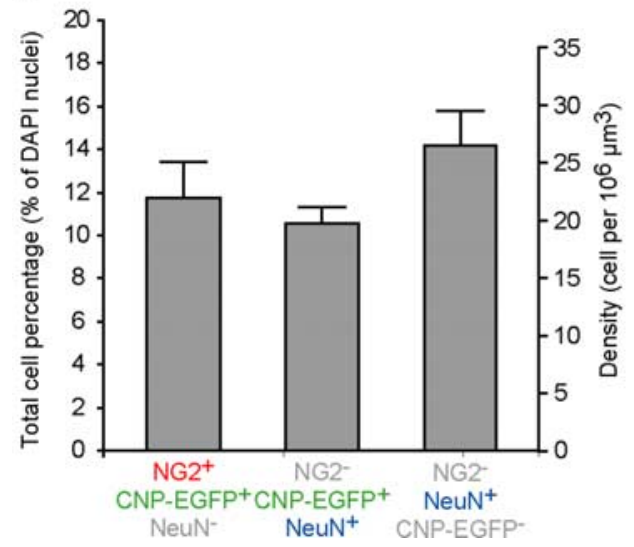

M

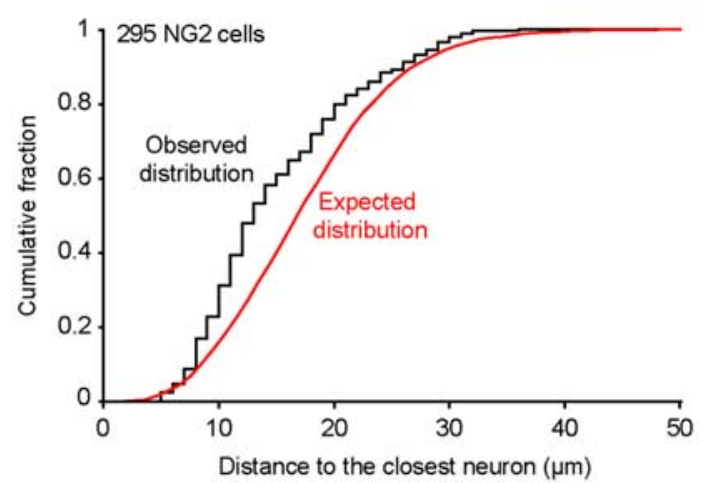

Figure 1. A fraction of $\mathrm{NG2}^{+}$cells are closely associated with CNP-EGFP ${ }^{+}$hilar interneurons. $A-C$, Single-plane confocal images showing the dentate gyrus of a P15 CNP-EGFP $(\boldsymbol{B})$ transgenic mouse immunostained for the proteoglycan NG2 (A). As shown on the merged image $(\boldsymbol{C})$, virtually all the brighter EGFP ${ }^{+}$fluorescent cells coexpress the proteoglycan NG2 (filled arrowheads). $\boldsymbol{D}-\mathbf{G}$, Single-plane confocal images showing the dentate gyrus of a P15 CNP-EGFP $(\boldsymbol{E})$ transgenic mouse immunostained for the proteoglycan NG2 (D) and the neuronal marker NeuN $(\boldsymbol{F})$. As shown on the merged image (G), NG2 ${ }^{+} \mathrm{EGFP}^{+}$cells are located close to both EGFP ${ }^{+} \mathrm{NeuN}^{+}$(filled arrowhead) and EGFP-negative NeuN ${ }^{+}$(open arrowhead) hilar neurons. The filled circles inside cell bodies indicate the center of each cell, as used for cell- cell distance measurement. $\boldsymbol{H}-\boldsymbol{K}$, Single-plane confocal images showing the dentate gyrus of a P15 CNP-EGFP $(\boldsymbol{I})$ transgenic mouse immunostained for GAD67 $(\boldsymbol{H})$ and the neuronal marker NeuN $(\boldsymbol{J})$. As shown on the merged image $(\boldsymbol{K}), \mathrm{EGFP}^{+} \mathrm{NeuN}^{+}$cells coexpress GAD67 (filled arrowhead) and can be found associated with brighter EGFP ${ }^{+}$ cells (black arrowhead), which are assumed to be NG2 ${ }^{+}$based on results shown in $\boldsymbol{A}-\mathbf{G}$. Scale bars, $20 \mu \mathrm{m}$. The filled circles inside cell bodies indicate the center of each cell, as used for cell-cell distance measurement. $L$, Bar graphs showing the percentage (left $y$-axis) of total hilar cells (based on DAPI counterstaining) that are NG2 ${ }^{+}$progenitors, $\mathrm{CNP}^{-E G F P}{ }^{+}$NeuN ${ }^{+}$neurons, and CNP-EGFP-negative NeuN ${ }^{+}$neurons and their corresponding density (right $y$-axis). Error bars indicate SEM. M, Cumulative plot showing the distribution of distances measured between 295 hilar $N G 2^{+}$cells and their closest neurons (black histogram), and the expected distribution of distances if cells were randomly distributed at the observed density (red trace).

Mann-Whitney $U$ test), and a significant increase in membrane capacitance from $19.6 \pm 4.6 \mathrm{pF}(\mathrm{P} 3-\mathrm{P} 5)$ to $26.5 \pm 3.6 \mathrm{pF}$ (P14P20) ( $p<0.01$, Mann-Whitney $U$ test). Therefore, the progressive integration of $s \mathrm{NG}^{+}$cells into the network is correlated with the maturation of their membrane properties.
We also observed a progressive maturation of glutamatergic synapses in $\mathrm{sNG} 2^{+}$cells. As illustrated in Figure 3, the average frequency of sEPSCs significantly increased from $0.07 \pm 0.02 \mathrm{~Hz}$ $(\mathrm{P} 3-\mathrm{P} 6 ; n=9)$ to $0.13 \pm 0.04 \mathrm{~Hz}(\mathrm{P} 14-\mathrm{P} 20 ; n=9)(p<0.01$, Mann-Whitney $U$ test) (Fig. $3 B$ ), and their average amplitude 
A

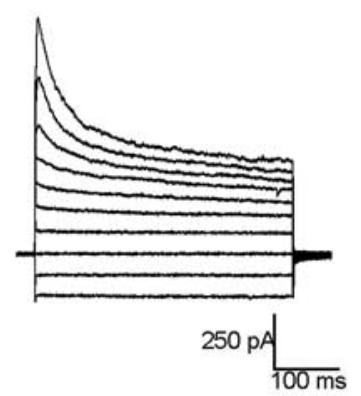

B

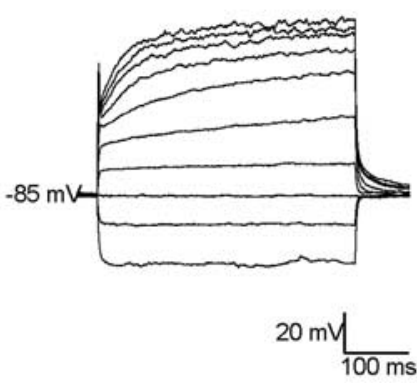

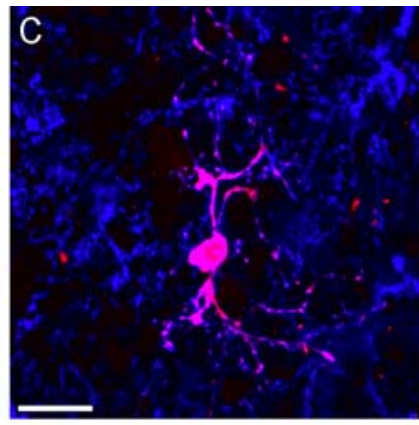

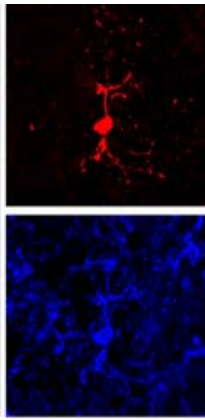

D

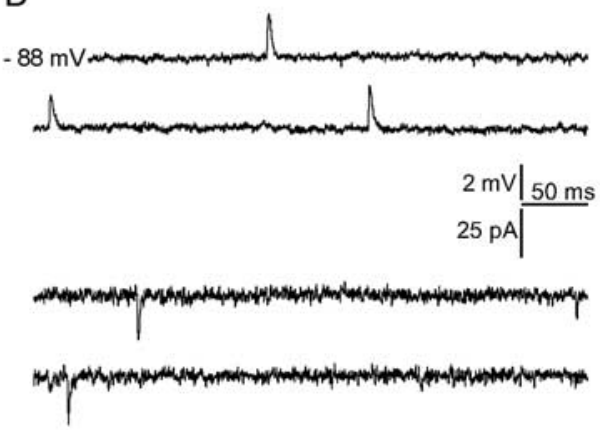

$\mathrm{E}$

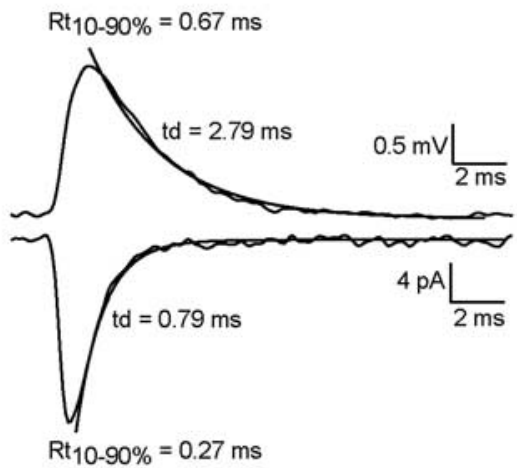

$\mathrm{F}$

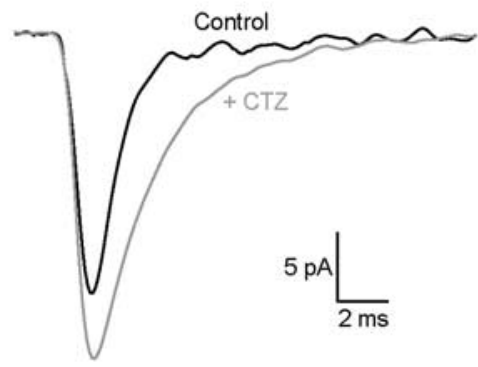

G

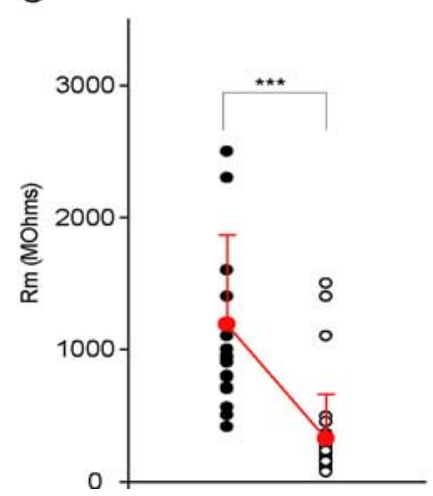

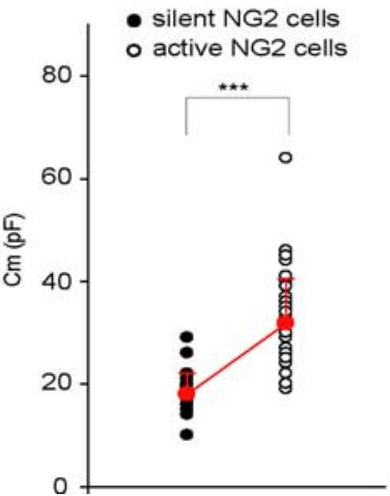

Figure 2. A subpopulation of hilar $s \mathrm{NG2}^{+}$cells receives a glutamatergic input and exhibits distinct membrane properties. $\boldsymbol{A}, \boldsymbol{B}$, Representative responses in voltage-clamp $(\boldsymbol{A})$ and current-clamp $(\boldsymbol{B})$ mode of a sNG2 ${ }^{+}$EGFP $^{+}$cell to voltage steps $(\boldsymbol{A})(-100$ to $-10 \mathrm{mV}$; step size, $10 \mathrm{mV})$ and current injection $(\boldsymbol{B})(-100-350 \mathrm{pA}$; step size, $50 \mathrm{pA})$. C, Single-plane confocal merged image (left) showing an example of a bright EGFP ${ }^{+}$cell expressing the proteoglycan NG2 (bottom right) and filled with biocytin (top right) during patch-clamp recording. Scale bar, $20 \mu \mathrm{m}$. $\boldsymbol{D}$, Representative examples of current-clamp (top traces) and voltage-clamp $\left(V_{\mathrm{h}}=-80 \mathrm{mV}\right.$ ) (bottom traces) recordings from a sNG2 ${ }^{+}$EGFP ${ }^{+}$cell exhibiting spontaneous synaptic glutamatergic activity. $\boldsymbol{E}$, Average traces of sEPSPs (top trace) and sEPSCs (bottom trace) recorded from the cell shown in $\boldsymbol{D}$. Average sEPSPs and sEPSCs exhibit a fast-rising phase ( 0.67 and $0.27 \mathrm{~ms}$, respectively) and a decay time ( 2.79 and $0.79 \mathrm{~ms}$, respectively) typical of synaptic events mediated by AMPA/kainate receptors. $\boldsymbol{F}$, Average of sEPSCs recorded under control conditions (black trace) and in the presence of $100 \mu \mathrm{m}$ CTZ (gray trace). Sensitivity to CTZ indicates that these sEPSCs are mediated by AMPA receptors $\left(V_{\mathrm{h}}=-80 \mathrm{mV}\right)$. G, Plots showing the individual membrane resistance (left plot) and capacitance (right plot) values of NG2 ${ }^{+}$cells recorded between P9 and P13 in which no sEPSCs were observed (black circles, silent cells) and NG2 ${ }^{+}$cells exhibiting sEPSCs (white circles, active cells). Average values (red circles) and SDs (red bars) are indicated for each cell population. All recordings were performed in the presence of $100 \mu \mathrm{m}$ picrotoxin using a K-gluconate internal solution. ${ }^{* * *} p<0.001$.

significantly increased from $12.6 \pm 3.7 \mathrm{pA}(\mathrm{P} 3-\mathrm{P} 6)$ to $19.8 \pm 3.4$ pA (P14-P20) $(p<0.05$, Mann-Whitney $U$ test $)($ Fig. 3C). During the same time period, we observed a significant decrease in sEPSC $20-80 \%$ rise time from $0.34 \pm 0.05 \mathrm{~ms}$ (P3-P6) to $0.25 \pm$ $0.06 \mathrm{~ms}$ (P14-P20) $(p<0.01$, Mann-Whitney $U$ test) (Fig. 3D) and a significant decrease in sEPSC decay time constant from $1.46 \pm 0.16 \mathrm{~ms}$ (P3-P6) to $1.08 \pm 0.2 \mathrm{~ms}(\mathrm{P} 14-\mathrm{P} 20)(p<0.01$, Mann-Whitney $U$ test) (Fig. $3 E$ ). In conclusion, similar to neurons (Takahashi, 2005), sNG2 ${ }^{+}$cells exhibit evidence of matura- tion of their glutamatergic synapses during the first 3 postnatal weeks.

Hilar interneurons and their $\mathrm{sNG} 2{ }^{+}$cells are similarly integrated into the hippocampal network

To define the origin of glutamatergic inputs in hilar sNG2 ${ }^{+}$cells and $\mathrm{EGFP}^{+}$interneurons, we recorded responses to electrical stimulation (100 $\mu$ s duration; $10-500 \mu \mathrm{A}$ intensity) of the two main populations of excitatory neurons known to contact hilar 
A
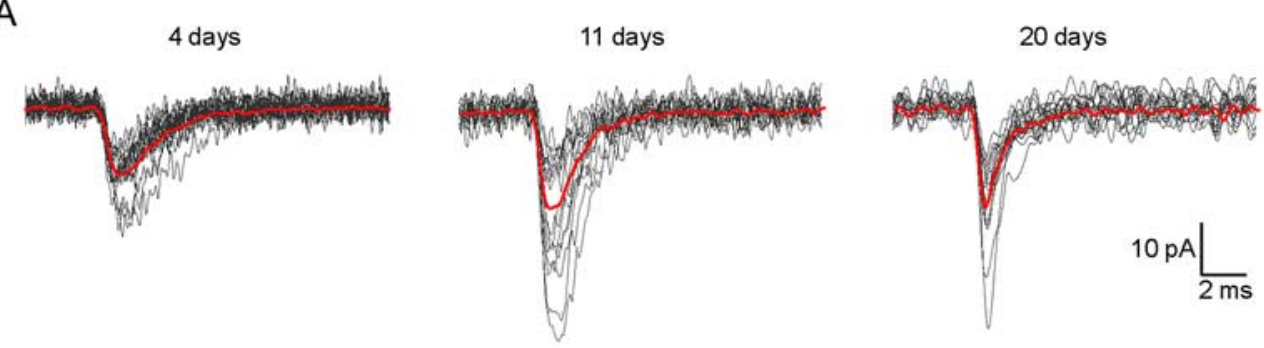

B

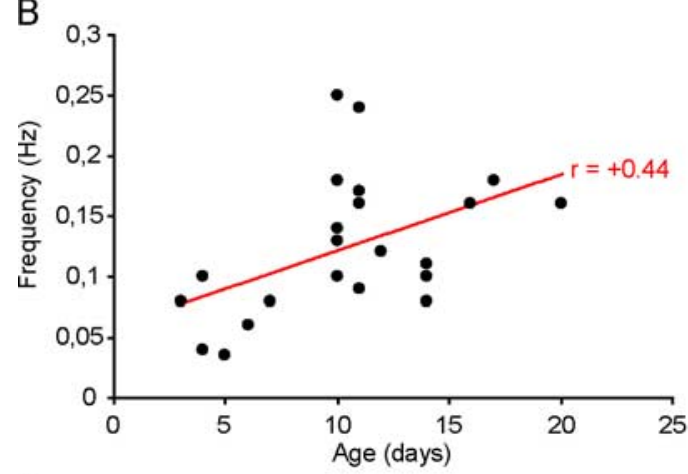

D

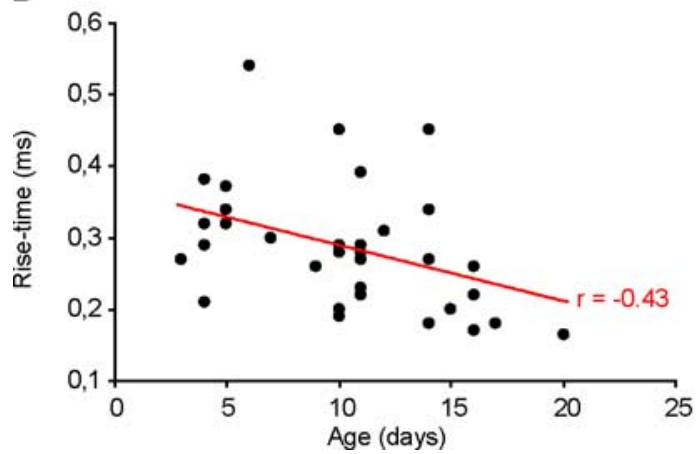

C

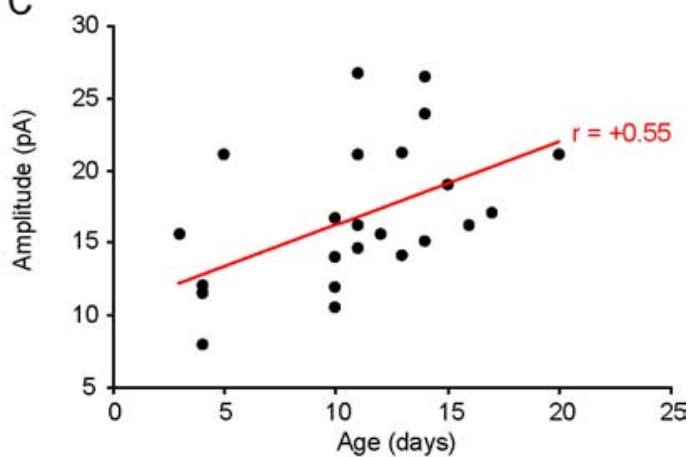

$\mathrm{E}$

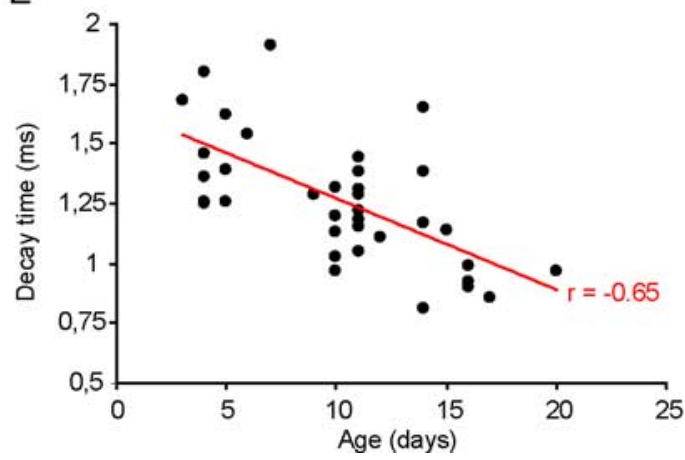

Figure 3. Hilar $\mathrm{NG2}{ }^{+}$cells are progressively integrated into the network during postnatal development and their inputs exhibit functional maturation. $A$, Examples of 15 individual EPSCs (gray traces) and the corresponding averaged trace (red traces) recorded in three representative sNG2 ${ }^{+}$cells at P4 (left), P11 (middle), and P20 (right). $\boldsymbol{B}$, Scatter plot of the sEPSC frequency ( $y$-axis) in

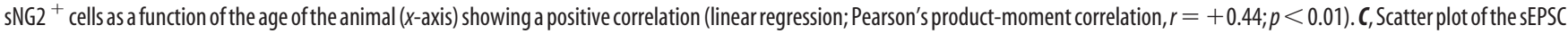
average amplitude ( $y$-axis) in sNG2 ${ }^{+}$cells as a function of the age of the animal ( $x$-axis) showing a positive correlation (linear regression; Pearson's product-moment correlation, $r=0.55 ; p<$ 0.01). D, Scatter plot of the SEPSC $20-80 \%$ rise time ( $y$-axis) in SNG2 ${ }^{+}$cells as a function of the age of the animal ( $x$-axis) showing a negative correlation (linear regression; Pearson's product-moment correlation, $r=-0.43 ; p<0.01$ ). $\boldsymbol{E}$, Scatter plot of the sEPSC decay time constant ( $y$-axis) in sNG2 ${ }^{+}$cells as a function of the age of the animal ( $x$-axis) showing a negative correlation (linear regression; Pearson's product-moment correlation, $r=-0.65 ; p<0.001$ ). All recordings were performed in the presence of $100 \mu \mathrm{M}$ CTZ using a K-gluconate internal solution.

neurons: dentate granule cells and CA3 pyramidal neurons (Scharfman, 1994a,b). All recordings were performed in the presence of $100 \mu \mathrm{M}$ picrotoxin to block GABAergic inhibitory currents.

In an isolated dentate gyrus slice (see Materials and Methods), stimulation of the granule cell layer evoked monosynaptic EPSCs in $\mathrm{sNG} 2{ }^{+}$cells with an average amplitude of $62 \pm 8 \mathrm{pA}\left(V_{\mathrm{h}}=\right.$ $-80 \mathrm{mV} ; n=8$ ) (Fig. $4 \mathrm{~B}$ ). The same stimulation protocol also evoked a monosynaptic response in $\mathrm{EGFP}^{+}$interneurons, with an average amplitude of $670 \pm 363 \mathrm{pA}\left(V_{\mathrm{h}}=-60 \mathrm{mV} ; n=6\right)$ (Fig. $4 A$ ). In both cell types, evoked responses were completely blocked by the AMPA/kainate glutamate receptor (GluR) antagonist CNQX $(50 \mu \mathrm{M})$ (data not shown) $(n=3)$.

It has been previously shown that the activation of group II metabotropic glutamate receptors (mGluRs) strongly and selectively depresses glutamate release from the mossy fibers of granule cells (Shigemoto et al., 1997). Indeed, application of $1 \mu \mathrm{M}$ DCG-IV, a group II mGluR agonist, strongly reduced evoked EPSCs by $75 \pm 15 \%\left(\right.$ SEM) in NG2 ${ }^{+}$cells $(n=6)$ and by $88 \pm$
$10 \%$ in hilar CNP-EGFP ${ }^{+}$interneurons $(n=4)$ (Fig. $\left.4 A, B\right)$. Mossy fibers also exhibit a strong pair-pulse facilitation, both in CA3 pyramidal neurons and in a subpopulation of interneurons (Salin et al., 1996; Toth et al., 2000). When paired stimuli were applied at minimal intensity with a $50 \mathrm{~ms}$ interstimulus interval, the amplitude of the second response increased by $174 \pm 20 \%$ in sNG2 ${ }^{+}$cells $(n=4)$ and by $208 \pm 40 \%$ in $\mathrm{EGFP}^{+}$interneurons $(n=4)$ (Fig. $4 C, D)$. Therefore, both cell types are contacted by mossy fiber synapses exhibiting similar paired-pulse facilitation. Together, these results indicate that both hilar sNG2 ${ }^{+}$cells and $\mathrm{EGFP}^{+}$interneurons receive a synaptic input from mossy fiber synapses, which exhibit similar pharmacological modulation and short-term plasticity. However, the maximal synaptic response was drastically smaller in $\mathrm{sNG}^{+}$cells than in $\mathrm{EGFP}^{+}$ interneurons.

We then used whole hippocampal slices (see Materials and Methods) to explore the possible existence of recurrent excitatory synapses from CA3 pyramidal neurons onto hilar $\mathrm{sNG}^{+}$cells and $\mathrm{EGFP}^{+}$interneurons. Figure $4, E$ and $F$, shows examples of 
A

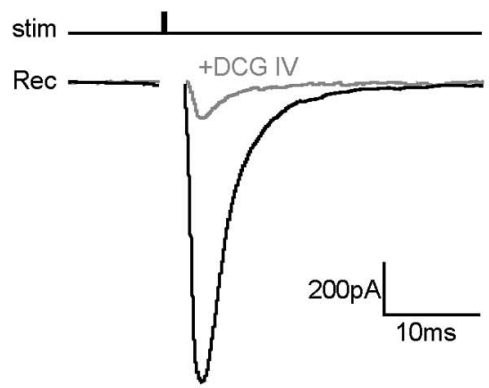

B

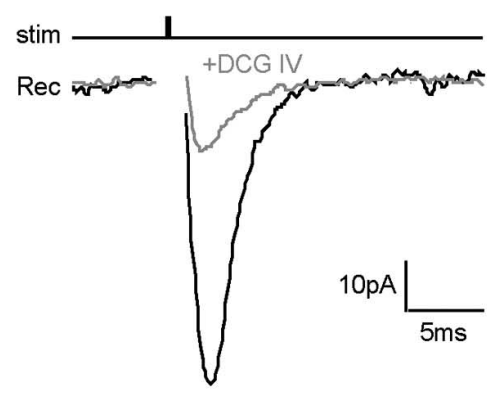

C

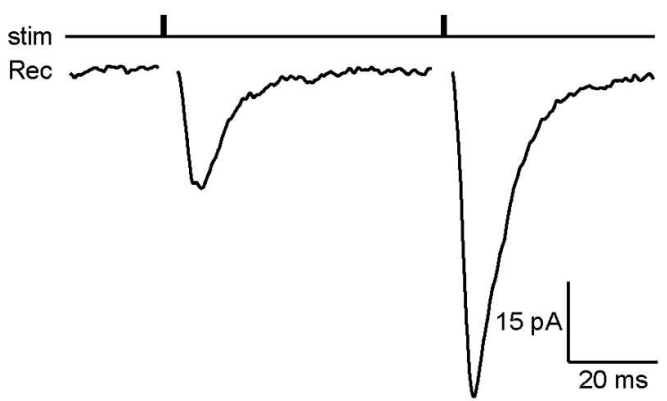

D

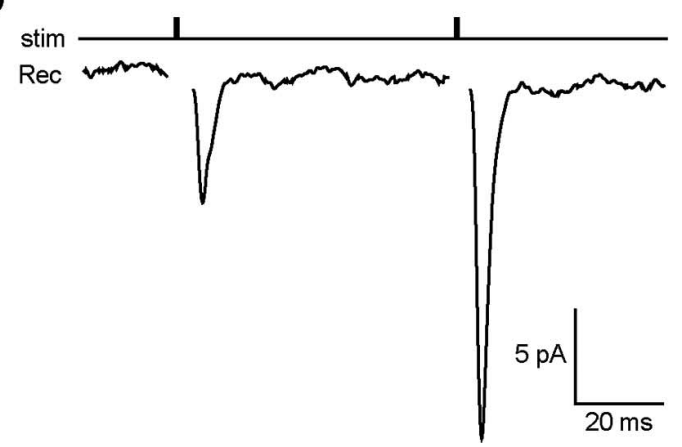

E

stim -

Rec
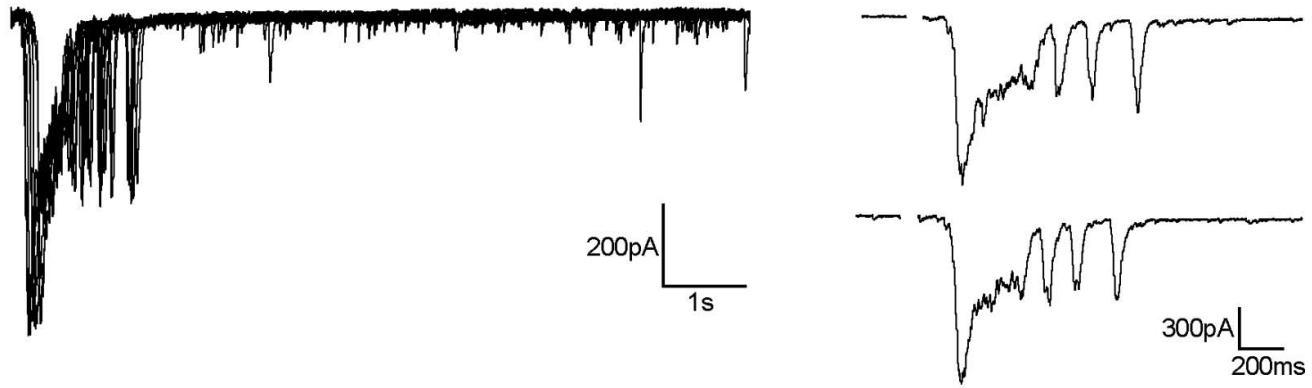

F

stim -1

Rec
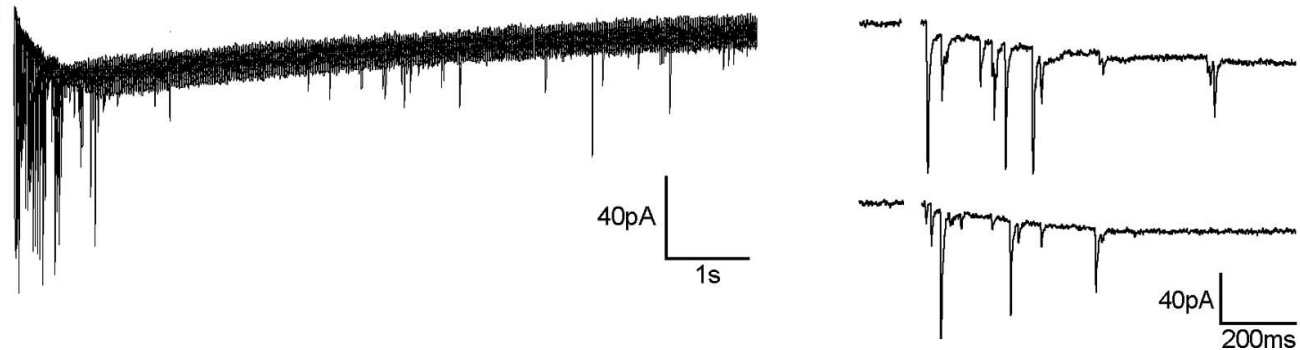

Figure 4. $\quad$ sNG2 ${ }^{+}$cells and EGFP ${ }^{+}$hilar interneurons receive glutamatergic inputs both from granule cells and CA3 pyramidal neurons. $A, B$, Evoked responses to granule cell layer stimulation in a hilar EGFP ${ }^{+}$interneuron $(A)\left(V_{\mathrm{h}}=-60 \mathrm{mV}\right)$ and its $\mathrm{NGG}{ }^{+}$cell $(\boldsymbol{B})\left(V_{\mathrm{h}}=-80 \mathrm{mV}\right)$ under control conditions (black trace) and in the presence of $1 \mu \mathrm{m} \mathrm{DCG-IV} \mathrm{(gray} \mathrm{trace).} \mathrm{Traces} \mathrm{are} \mathrm{averaged}$ from 25 consecutive responses recorded from the same cell in the voltage-clamp mode (stimulus: $100 \mu \mathrm{s}, 200 \mu \mathrm{A}$ ). The significant reduction of the evoked response after application of DCG-IV indicates that both cell types are contacted by mossy fiber synapses. Responses were evoked in an isolated dentate gyrus slice preparation. $C, D$, Facilitation of evoked responses by paired minimal stimulation of the granule cell layer (interstimulus interval, $50 \mathrm{~ms})$ in a hilar EGFP ${ }^{+}$interneuron $(C)\left(V_{\mathrm{h}}=-60 \mathrm{mV}\right)$ and its sNG2 ${ }^{+}$cell $(\boldsymbol{D})\left(V_{\mathrm{h}}=-80 \mathrm{mV}\right)(\mathrm{stimulus}: 100 \mu \mathrm{s}, 10 \mathrm{and} 50 \mu \mathrm{A})$. The traces are averaged from 25 consecutive responses recorded from the same cell in the voltage-clamp mode. $\boldsymbol{E}, \boldsymbol{F}$, Superposition of consecutive responses evoked by CA3 layer stimulation in a hilar EGFP $^{+}$interneuron $(\boldsymbol{E})\left(V_{\mathrm{h}}=-60 \mathrm{mV}\right)$ and its sNG2 ${ }^{+}$cell $(\boldsymbol{F})\left(V_{\mathrm{h}}=-80 \mathrm{mV}\right)($ stimulus: $100 \mu \mathrm{s}, 200 \mu \mathrm{A})$. The right traces show examples of single responses evoked by $\mathrm{CA} 3$ layer stimulation in both cell types. All recordings were performed in the presence of $100 \mu \mathrm{M}$ CTZ and $100 \mu \mathrm{m}$ picrotoxin using a K-gluconate internal solution. stim, Stimulus; Rec, recording.

responses evoked in both cell types by stimulation of the CA3 pyramidal layer. In hilar interneurons (Fig. $4 E$ ), we observed an initial large polysynaptic response with an average amplitude of $1280 \pm 590 \mathrm{pA}$, lasting up to $400 \mathrm{~ms}(n=10)$. This main response was usually followed by a burst of 3-20 recurrent events lasting up to $5 \mathrm{~s}$. In sNG2 ${ }^{+}$cells (Fig. $4 F$ ), the same protocol induced a burst of EPSCs (range, 5-30 events) lasting from $500 \mathrm{~ms}$ to several seconds and with a maximal amplitude of $105 \pm 17 \mathrm{pA}(n=8)$. 
sNG2 ${ }^{+}$cells also exhibited a slow inward current, not seen in hilar interneurons, which rises as long as the EPSC bursts last and decays with a monoexponential time constant between 2 and $10 \mathrm{~s}$. The putative nature and origin of this slow current will be considered in the next section (see below). In the absence of any stimulation, spontaneous bursts of EPSCs occurred in both cell types, and resembled bursts evoked by CA3 stimulation. Such spontaneous bursts have been reported in the CA3 area when hippocampal slices are disinhibited by the application of GABAergic antagonists (Miles and Wong, 1987; Cohen et al., 2006). Consistent with these previous findings, our recordings of hilar interneurons and $\mathrm{sNG} 2{ }^{+}$cells revealed no bursts under control conditions, but subsequent application of $100 \mu \mathrm{M}$ picrotoxin induced bursts in most cells after $10 \mathrm{~min}$ (data not shown) $(n=4$ of 5$)$. In contrast, application of $100 \mu \mathrm{M}$ picrotoxin failed to induce any bursts when the CA3 area was removed from the slice (data not shown) $(n=8)$.

Finally, when we stimulated the granule cell layer in whole hippocampal slices, the expected monosynaptic response in sNG2 ${ }^{+}$cells was usually followed by a burst of EPSCs after a delay of 40-60 ms (supplemental Fig. 2, available at www.jneurosci. org as supplemental material) $(n=4)$. Together, these results demonstrate that hilar $\mathrm{sNG} 2{ }^{+}$cells are contacted by both mossy fibers and CA3 pyramidal neurons.

\section{$\mathrm{sNG} 2{ }^{+}$cells do not receive synaptic contacts from closely} associated interneurons

We performed whole-cell patch-clamp paired recordings on pairs of closely associated hilar interneurons and $\mathrm{sNG} 2{ }^{+}$cells to determine whether they were directly connected (Fig. 5). $\mathrm{NG} 2{ }^{+}$cells were recorded at a holding potential of $0 \mathrm{mV}$ using a cesium-methanesulfonate internal solution with $E_{\mathrm{Cl}}=-80$ $\mathrm{mV}$ (see Materials and Methods). As shown in Figure $5 A$, spontaneous GABAergic IPSCs are clearly detectable in $\mathrm{sNG}^{+}{ }^{+}$cells under these recording conditions. In 23 pairs recorded, we were unable to evoke any IPSCs in $\mathrm{sNG} 2{ }^{+}$cells by stimulating their associated interneurons (Fig. 5D) (100200 trials per neuron; current injected, 50-200 pA, $600 \mathrm{~ms}, 1$ $\mathrm{Hz}$ ). We therefore concluded that few if any GABAergic synapses are formed by $\mathrm{EGFP}^{+}$interneurons directly onto their $s \mathrm{NG}_{2}{ }^{+}$cells. However, these results do not exclude the possibility that $\mathrm{EGFP}^{+}$interneurons contact $\mathrm{NG}^{+}{ }^{+}$cells that are not anatomically associated.

We also explored the possibility of a direct neuron-sNG2 cell connection via gap junction coupling, but never detected depolarization of the $\mathrm{SNG} 2^{+}$cells when interneurons were depolarized, or vice versa $(n=11)$. In this experiment, both cells were recorded in current-clamp mode using a K-gluconate internal solution. Neurons were depolarized to obtain a maximum firing rate (current injected, 50-200 pA, 100-200 sweep, 600 ms step, 1 $\mathrm{Hz}$ ) and $\mathrm{NG}^{+}$cells were depolarized up to $0 \mathrm{mV}(100-200$ sweep, 20-1000 pA, 600 ms step, $1 \mathrm{~Hz}$ ). Additionally, we observed no diffusion of biocytin or tetramethylrhodamine dextran from one cell to the other (Fig. $5 B$ ). Therefore, $s \mathrm{NG}^{+}$cells and $\mathrm{EGFP}^{+}$interneurons are unlikely to be connected by gap junctions. Finally, we investigated whether $\mathrm{EGFP}^{+}$interneurons might communicate with $\mathrm{NGG}{ }^{+}$cells via tonic release of GABA. However, in all sNG2 ${ }^{+}$cells tested (data not shown) $(n=5)$, no change was observed in the holding current when $3 \mu \mathrm{M}$ gabazine was applied.
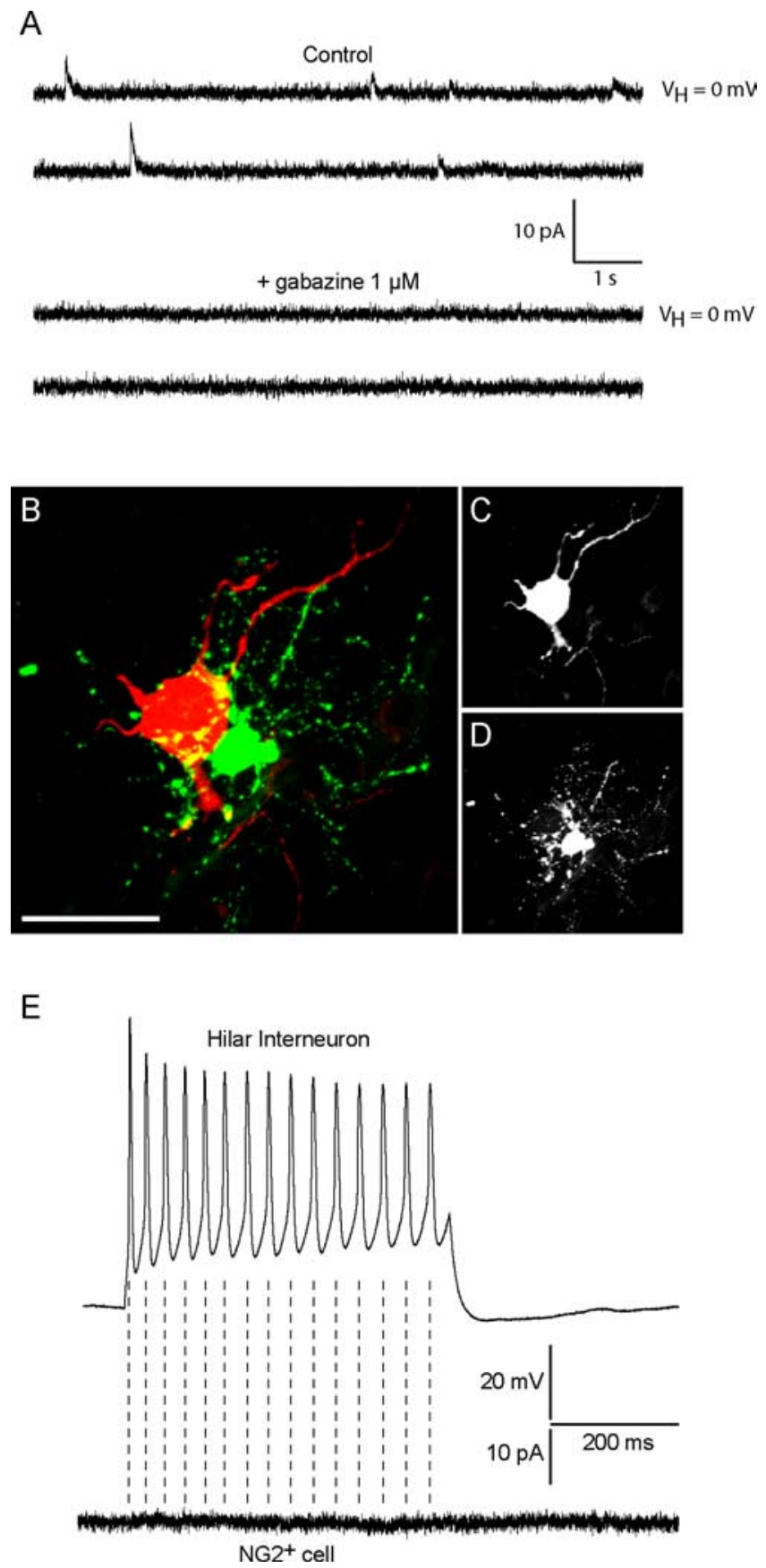

Figure 5. $\quad \mathrm{sNG2}{ }^{+}$cells are not directly contacted by associated hilar interneurons. $\boldsymbol{A}$, Example of spontaneous GABAergic IPSCs recorded in a sNG2 ${ }^{+}$cell (top traces) and blocked by $1 \mu \mathrm{m}$ gabazine (bottom traces). GABAergic activity was recorded using a (s-methanesulfonate solution $\left(V_{\mathrm{h}}=0 \mathrm{mV}\right.$; estimated $\left.E_{\mathrm{Cl}}=-80 \mathrm{mV}\right) . \boldsymbol{B}-\boldsymbol{D}$, Confocal images showing a hilar interneuron (red) and its sNG2 ${ }^{+}$cell (green) filled with biocytin (red in $\boldsymbol{B}$ and gray in $\boldsymbol{C}$ ) and tetramethylrhodamine dextran (green in $\boldsymbol{B}$ and gray in $\boldsymbol{D}$ ), respectively. Scale bar, $20 \mu \mathrm{m}$. $\boldsymbol{E}$, Example of a hilar interneuron (top trace) recorded in current clamp and its sNG2 ${ }^{+}$cell (bottom trace) recorded in voltage clamp. The injection of a current step in the interneuron (200 pA; $600 \mathrm{ms)}$ evoked a volley of action potentials, but did not evoke any response in the sNG2 ${ }^{+}$cell. The hilar neuron was recorded in $\mathrm{K}^{+}$-gluconate internal solution, whereas the $\mathrm{NG}^{+}{ }^{+}$cell was recorded in Cs-methanesulfonate solution and voltage clamped at $0 \mathrm{mV}\left(E_{\mathrm{Cl}}=-80 \mathrm{mV}\right)$. Our ability to detect GABAergic activity is demonstrated by the occurrence of spontaneous GABAergic IPSCs in some $\mathrm{NNG2}{ }^{+}$cells recorded under the same conditions.

Hilar interneurons and $\mathrm{sNG} 2^{+}$cells exhibit synchronized activity in disinhibited slices

Because both hilar interneurons and $s \mathrm{NG} 2^{+}$cells exhibit spontaneous bursts of glutamatergic activity in the presence of 
A

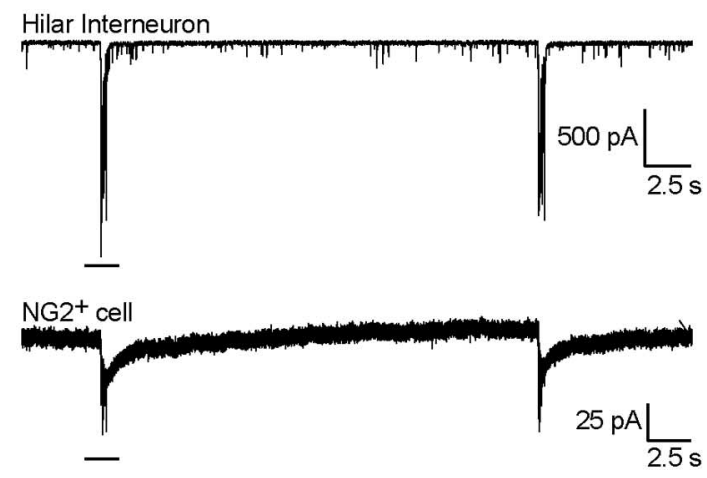

C

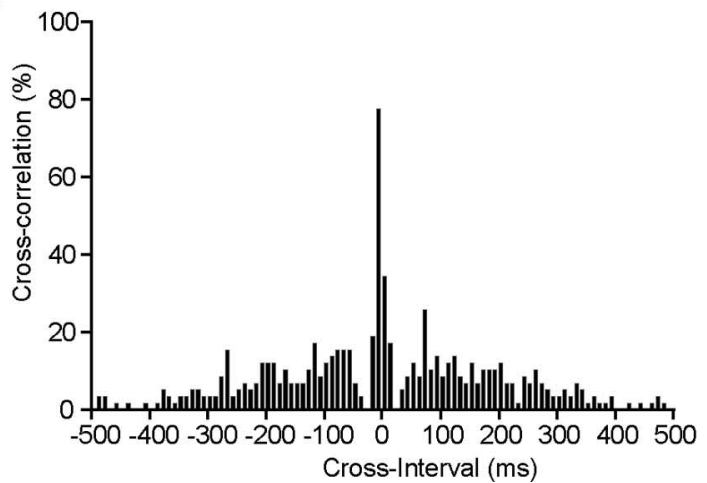

B

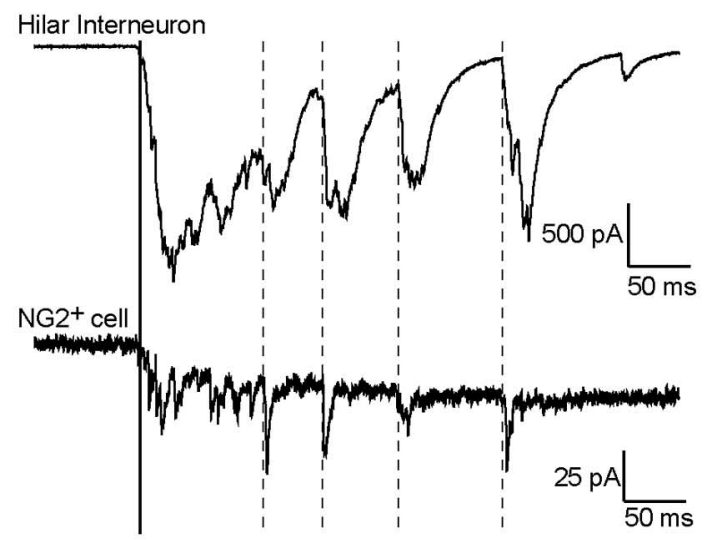

D

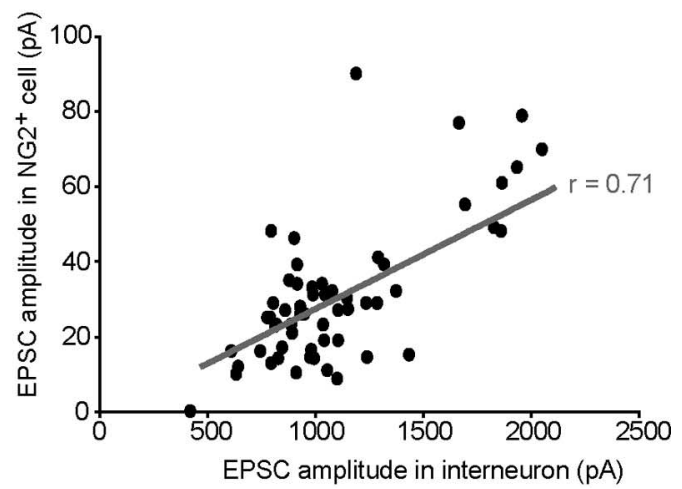

Figure 6. CA3 spontaneous bursts are synchronized between hilar interneurons and sNG2 ${ }^{+}$cells. $A$, Example of synchronized bursts observed in a hilar interneuron $\left(V_{\mathrm{h}}=-60 \mathrm{mV}\right)$ (top trace) and its sNG2 ${ }^{+}$cell $\left(V_{\mathrm{h}}=-80 \mathrm{mV}\right)$ (bottom trace) recorded in a whole hippocampal slice preparation in the presence of $100 \mu \mathrm{m}$ picrotoxin. The black bar indicates the interval of the trace in $A$ that is magnified in $\boldsymbol{B}$. B. Example of synchronized recurrent EPSCs observed within each burst in a hilar interneuron (top trace) and its sNG2 ${ }^{+}$cell (bottom trace). The dotted lines indicate recurrent EPSCS, which are usually observed after the initial discharge of EPSCs indicated by a solid line. C, Cross-correlation histogram shows the high degree of temporal correlation of recurrent EPSCs occurring in the interneuron and $\mathrm{NG2}{ }^{+}$cell shown in $\boldsymbol{A}$ and $\boldsymbol{B}$. A total of 57 recurrent events from 14 synchronized bursts were analyzed. Initial discharges were excluded from the analysis. Bin width, $5 \mathrm{~ms}$. $\boldsymbol{D}$, Scatter plot of the amplitudes of the recurrent EPSCs in the interneuron recorded in $\boldsymbol{A}$ and $\boldsymbol{B}$ ( $x$-axis) against the amplitudes of the corresponding EPSCs in the associated sNG2 ${ }^{+}$cell ( $y$-axis). EPSCs amplitudes in the interneuron and in the $\mathrm{NG}^{+}{ }^{+}$cell exhibit a positive correlation (gray linear regression; Pearson's product-moment correlation, $r=0.71 ; p<0.0001 ; 57$ synchronized events analyzed) and fit a linear relationship obtained by linear regression. As in C, a total of 57 recurrent events from 14 synchronized bursts were analyzed. Initial discharges were excluded from the analysis.

$\mathrm{GABA}_{\mathrm{A}} \mathrm{R}$ antagonists, we asked whether this activity was synchronized. In whole hippocampal slices, and in the presence of $100 \mu \mathrm{M}$ picrotoxin, we observed that bursts induced in hilar $\mathrm{EGFP}^{+}$interneurons and sNG2 ${ }^{+}$cells occurred simultaneously in all the pairs in which burst activity was observed (15 of 17 pairs) (Fig. 6A; supplemental Figs. 3, 4, available at www. jneurosci.org as supplemental material). Most $\mathrm{sNG}^{+}$cells exhibited both a burst of EPSCs and a slow inward current synchronized with bursts of EPSCs in interneurons $(n=11$ of 15$)$. Time correlation was typically evident within each burst. Both the initial EPSC discharge (Fig. 6B, solid line) and most recurrent EPSCs (Fig. $6 B$, dotted lines) were synchronized in $\mathrm{sNG}^{+}$cells and hilar interneurons (Fig. $6 B$ ). As illustrated in Figure $6 C$ for one of the pairs analyzed, cross-correlation analysis showed that most recurrent EPSCs are synchronized within a time window of $5 \mathrm{~ms}(81 \pm 7 \% ; n=4$ pairs; total of 216 EPSCs analyzed). A correlation was also observed between the amplitudes of each recurrent EPSC (for an example, see Fig. $6 D)(r=0.57 \pm 0.13$; $p<0.0001 ; n=4$ pairs; total of 216 EPSCs analyzed). Therefore, during periods of intense network activity, $\mathrm{sNG} 2{ }^{+}$cells exhibit a synchronized and proportional form of the activity arising in their associated interneurons.

Nonsynaptically connected NG2 ${ }^{+}$cells (4 of 15) also exhib- ited a synchronized slow inward current in the absence of any EPSCs, suggesting that such currents do not depend on the synaptic release of glutamate. Indeed, these slow currents were insensitive to NMDA-type GluR antagonist APV and to metabotropic GluR group I/II and group III antagonists ( $S)$-MCPG $[(S)$ - $\alpha$-methyl-4-carboxyphenylglycine $]$ and MSPG $[(R, S)-\alpha-2-$ methyl-4-sulfonophenylglycine] (data not shown) $(n=3)$. However, slight depolarization of $\mathrm{NG}^{+}$cells completely abolished the slow current at $-50 \mathrm{mV}$, which did not reverse at more depolarized potentials (data not shown) $(n=3)$. Finally, these slow currents could be suppressed by the use of an internal solution containing $\mathrm{Cs}^{+}$, known to block potassium channels (supplemental Fig. 4, available at www.jneurosci.org as supplemental material). Together, these results suggest that the slow current is mediated by potassium channels that remain open at a hyperpolarized membrane potential. We hypothesize that this current might result from a transient modification of the $\mathrm{K}^{+}$reversal potential caused by the release of large amounts of $\mathrm{K}^{+}$into the extracellular medium by CA3 recurrent fibers firing synchronously, as described during epileptic activity (Avoli et al., 1996). Similar slow currents have been described in hippocampal astrocytes in response to Schaffer collateral stimulation, and have also 
been associated with an increase in extracellular potassium (Bergles and Jahr, 1997).

\section{Hilar interneurons and $s \mathrm{NG} 2{ }^{+}$cells receive synaptic contacts from the same neurons}

The experiments described above demonstrate that activity of hilar $\mathrm{EGFP}^{+}$interneurons and $\mathrm{sNG} 2^{+}$cells can be synchronized when a large group of presynaptic neurons are synchronized in disinhibited slices (i.e., in a frequently used model of epileptic activity). Nevertheless, we wanted to explore whether hilar interneurons and $\mathrm{sNG} 2{ }^{+}$cells could also be synchronized under more normal physiological conditions (i.e., in the absence of GABAergic antagonist).

Oscillations in the gamma and theta frequency characterize the activity of the hippocampus in vivo and can be reliably induced in vitro by the application of cholinergic agonists, such as carbachol (Fischer, 2004). In vitro, such oscillations depend on the synchronization of CA3 pyramidal neurons and are thought to spread to the dentate gyrus via CA3 recurrent fibers (Fischer, 2004; Scharfman, 2007). Indeed, when we bath-applied $20 \mu \mathrm{M}$ carbachol to a whole hippocampal slice, we observed a strong increase in sEPSC frequency in $\mathrm{EGFP}^{+}$hilar interneurons, which correlated with the emergence of theta oscillations in the CA3c area (frequency, $10.1 \pm 0.8 \mathrm{~Hz} ; n=5$ ) (supplemental Fig. 5, available at www.jneurosci.org as supplemental material). Importantly, this increase in sEPSC frequency was reversed by the application of TTX $(n=3)$ (supplemental Fig. 5, available at www.jneurosci.org as supplemental material), demonstrating that this effect depended on the network itself, rather than on direct activation of presynaptic nicotinic or metabotropic acetylcholine receptors. Moreover, isolating the dentate gyrus from the CA3 area did not significantly increase the sEPSC frequency in hilar interneurons on carbachol application $(n=3)$ (supplemental Fig. 5, available at www.jneurosci.org as supplemental material), which suggested that the cholinergic agonist specifically increased sEPSC frequency from CA3 pyramidal neurons.

When we recorded hilar $\mathrm{EGFP}^{+}$interneuron/sNG2 ${ }^{+}$cell pairs in the presence of $20 \mu \mathrm{M}$ carbachol, a parallel increase in sEPSC frequency was observed in both cells (Fig. 7A). The average EPSC frequency increased by $430 \pm 152 \%$ in $\mathrm{sNG}^{+}$cells (from 0.15 to $0.65 \mathrm{~Hz} ; n=19$ ) and by $490 \pm 290 \%$ in hilar interneurons (from 5.3 to $26 \mathrm{~Hz} ; n=19$ ). However, the amplitude distribution of sEPSCs was unaffected by carbachol both in interneurons (Fig. $7 B$ ) and in sNG2 ${ }^{+}$cells (Fig. 7C), suggesting that most carbachol-induced sEPSCs did not arise from synchronized firing of several pyramidal neurons.

More importantly, we observed synchronized EPSCs between closely associated pairs of cells (Fig. 7D). To confirm and quantify the proportion of synchronized events, we plotted the delay between sEPSCs occurring in $\mathrm{sNG} 2{ }^{+}$cells and in associated interneurons. As illustrated by the cross-correlogram in Figure 7E, the pooled distribution of the delays obtained from eight pairs showed a clear peak around $0 \mathrm{~ms}$. On average, 14\% of the interevent intervals were above the noise level (chance correlation) and within a time window of $\pm 1 \mathrm{~ms}$ (Fig. $7 E$ ). In contrast, when we pooled recordings from pairs of cells separated by $>200 \mu \mathrm{m}$, the fraction of synchronized events represented $4 \%$ of sEPSCs recorded from six cell pairs (Fig. $7 F$ ). We still observed a significant difference ( $p<0.01$, Mann-Whitney $U$ test) between close and distant pairs of cells when comparing the percentage of synchronized events above the noise level in each individual pair of cells (Fig. 7G).

Because the application of carbachol did not affect the sEPSC amplitude distribution in either cell type, it seemed likely that most synchronized sEPSCs were attributable to the firing of a single presynaptic neuron that contacted both cells.

\section{Hilar interneurons and their $\mathrm{sNG} 2{ }^{+}$cells are activated by distinct presynaptic contacts}

To define whether the synchronous sEPSCs observed in the presence of carbachol could arise from a common active zone, we recorded the miniature EPSC (mEPSC) activity in pairs of hilar $\mathrm{EGFP}^{+}$interneurons/sNG2 ${ }^{+}$cells. In the presence of TTX, the frequency of mEPSCs in NG2 ${ }^{+}$cells was usually too low to permit any significant analysis. Therefore, we used a method initially developed by Auger and Marty (1997) to induce repetitive release of neurotransmitter from the same active zone by transiently applying a low concentration of latrotoxin (0.1-1.0 nM) followed by perfusion with a low calcium concentration solution (Auger and Marty, 1997; Rigo et al., 2003). Figure 8 shows bursts of mEPSCs induced by such a protocol in a hilar EGFP ${ }^{+}$interneuron and its $\mathrm{sNG} 2{ }^{+}$cell. Under these experimental conditions, we never observed any simultaneous bursts of mEPSCs in both cells $\left(N_{\text {pair }}=33\right)$. Moreover, cross-correlogram analysis demonstrated an absence of nonrandom simultaneous mEPSCs between both cells $(n=8)$. These results demonstrate that $\mathrm{sNG} 2^{+}$ cells and hilar interneurons are synchronously activated by the release of glutamate from two distinct active zones, rather than by a spillover mechanism. This observation is also consistent with the finding that sEPSCs recorded in $\mathrm{SNG}_{2}{ }^{+}$cells exhibit fast rise and decay time constants, incompatible with activation by spillover (Fig. 2E) (Paukert and Bergles, 2006).

\section{Discussion}

Close anatomical proximity of $\mathrm{NG}_{2}{ }^{+}$progenitor cells with principal excitatory neurons has been described in various areas of the nervous system, including cerebellum, cerebral cortex, and hippocampus (Butt et al., 2005; Dayer et al., 2005; Lin et al., 2005). In gray matter, $\mathrm{NG} 2{ }^{+}$processes are usually intertwined with neuronal dendrites, whereas their somata are frequently apposed to neuronal cell bodies. In the present study, $\mathrm{NG}^{+}$cells were found anatomically associated with interneurons in the hilus of the dentate gyrus. The use of the CNP-EGFP transgenic mouse allowed us to perform paired recordings in hilar interneurons and their $\mathrm{sNG}_{2}{ }^{+}$cells. We demonstrate that these $\mathrm{sNG} 2{ }^{+}$cells are integrated into the local network much like their neuronal counterparts, and receive the same excitatory inputs from mossy fibers and recurrent collaterals of CA3 pyramidal neurons. Finally, we provide evidence that closely associated $\mathrm{sNG} 2^{+}$/interneuron pairs are more frequently contacted by the same neurons than are spatially separated cells. Because of this common network integration, $\mathrm{sNG}_{2}{ }^{+}$cells have the ability to reflect, at lower amplitude, the patterns of activity displayed by local interneurons.

\section{Hilar $\mathrm{sNG} 2{ }^{+}$cells can detect changes in the activity of the local network}

This study shows that most $\mathrm{sNG} 2^{+}$cells associated with hilar interneurons are synaptically connected during the first postnatal weeks, as they acquire more mature membrane properties. Thus, our analysis confirms the observation that most $\mathrm{NG}^{+}$cells receive glutamatergic synaptic contacts postnatally, both in gray matter and white matter areas (Bergles et al., 2000; Bergles, 2005; Jabs et al., 2005; Lin et al., 2005; Kukley et al., 2007; Ziskin et al., 2007). A recent study demonstrated that even $\mathrm{NG} 2^{+}$cells newly generated by symmetrical division inherit synapses from their parent cell in the postnatal hippocampus (Kukley et al., 2008). 

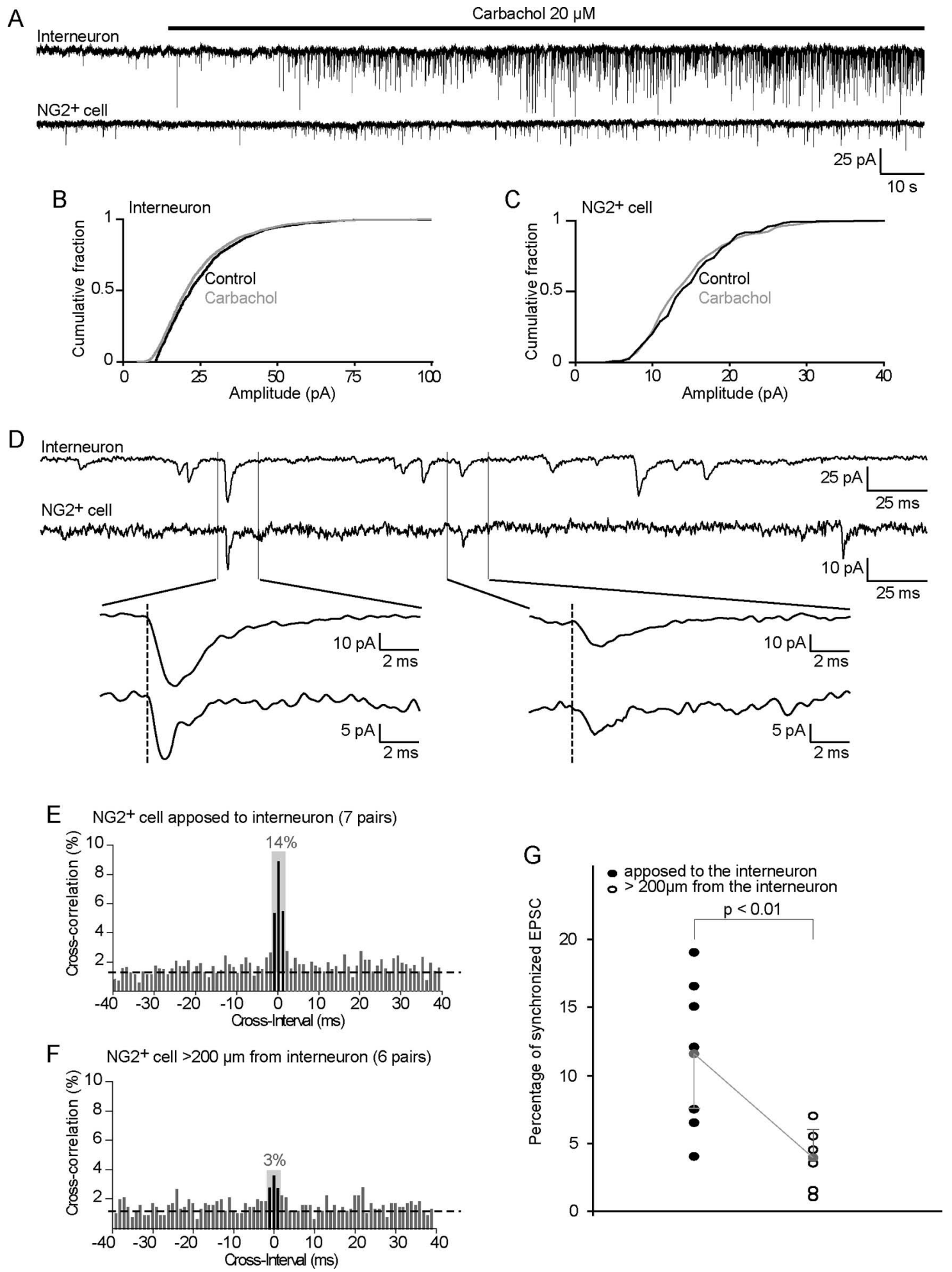

Figure 7. $\quad \mathrm{sNG2}{ }^{+}$cells and hilar interneurons are contacted by the same neuron. $A$, Example of spontaneous activity recorded in a hilar interneuron $\left(V_{\mathrm{h}}=-60 \mathrm{mV}\right)\left(\right.$ top trace) and its sNG2 ${ }^{+}$ cell $\left(V_{\mathrm{h}}=-80 \mathrm{mV}\right)$ (bottom trace) using a specific cesium-methanesulfonate internal solution to isolate EPSCs while preserving GABAergic activity $\left(E_{\mathrm{Cl}}=-80 \mathrm{mV} ; E_{\text {cation }}=0 \mathrm{mV}\right)$. The application of $20 \mu \mathrm{m}$ carbachol to the hippocampal slice strongly increases the spontaneous EPSC activity in both cells. B, C, Cumulative plots of the amplitudes of EPSCS observed in the absence (black) and presence (gray) of $20 \mu \mathrm{m}$ carbachol. EPSC amplitude distributions are not significantly affected by the application of carbachol, either in the interneuron (B) or in its sNG2 ${ }^{+}$cell $(\boldsymbol{C})$. $\boldsymbol{D}$, Example of synchronized spontaneous activity recorded in the hilar interneuron (top trace) and sNG2 ${ }^{+}$cell (bottom trace) shown in $\boldsymbol{A}$. The bottom traces show two examples of synchronized EPSCs. $\boldsymbol{E}$, Cross-correlation histogram shows that a significant fraction of EPSCs are synchronized between interneurons and their sNG2 ${ }^{+}$cells. The histograms are from data pooled from eight sNG2 ${ }^{+}$ cell-interneuron pairs. The gray box highlights events that are in a time window of $\pm 1 \mathrm{~ms}$ and above the noise level (corresponding to random correlations). $\boldsymbol{F}$, (ross-correlation histogram shows that only a few EPSCs are synchronized when interneurons and sNG2 ${ }^{+}$cells are separated by $>200 \mu \mathrm{m}$. The histograms show data pooled from seven sNG2 ${ }^{+}$cell-interneuron pairs. The gray box highlights events that are in a time window of $\pm 1 \mathrm{~ms}$ and above the noise level (corresponding to random correlations). G, Plot of the percentage of synchronized events above the noise level in each recorded cell pair showing a significant difference ( $p<0.01$, Mann-Whitney $U$ test) between pairs of anatomically associated cells $(11.6 \pm 4.2 \% ; n=7)$ versus pairs of distant cells $(3.8 \pm 1.8 \%$; $n=6)$. 
A

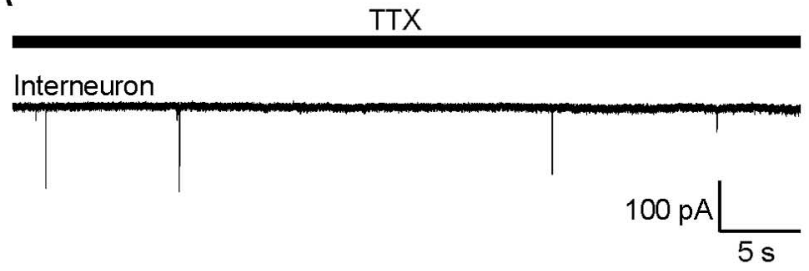

$\mathrm{NG} 2^{+}$cell

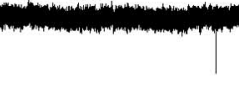

After 5 min in LTX
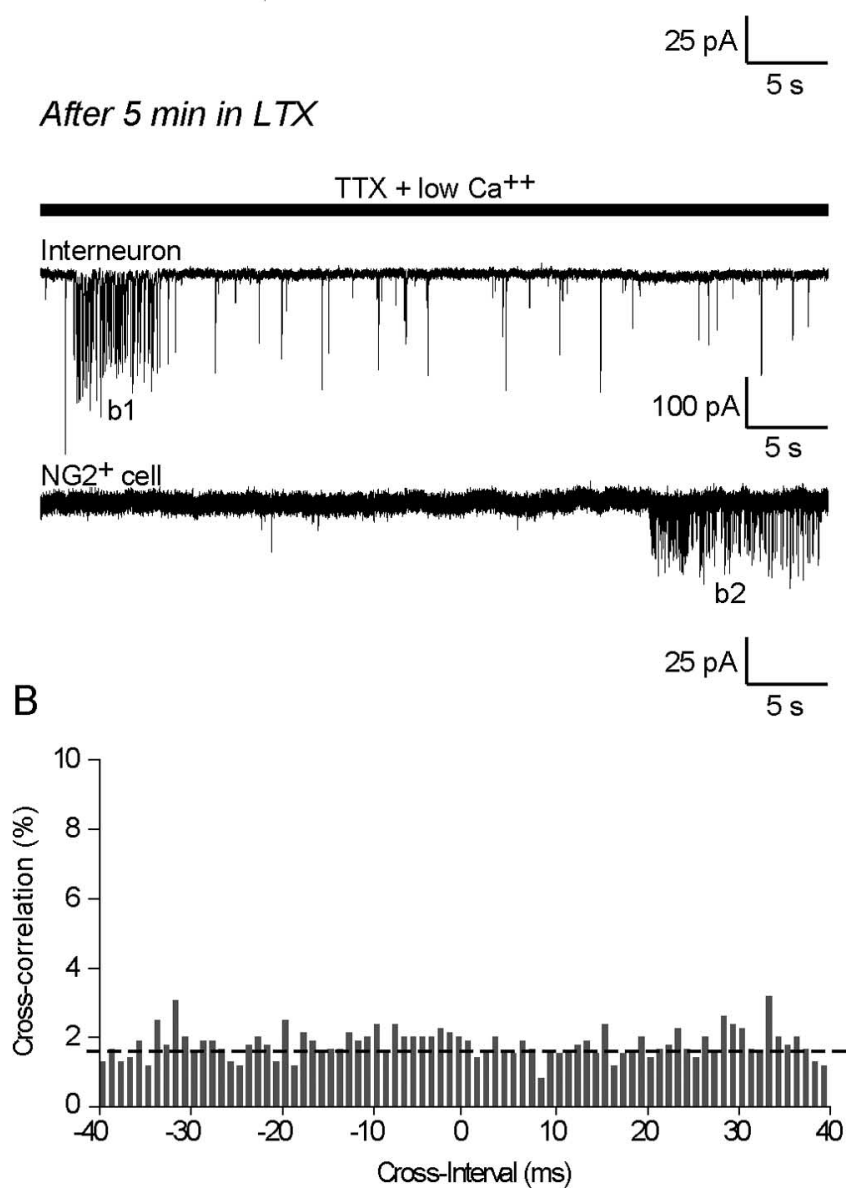

Figure 8. $\quad s \mathrm{NG}^{+}$cells and hilar interneurons do not respond to the same excitatory synapses, despite their close spatial association. $\boldsymbol{A}$, Example of mEPSC activity recorded in a hilar $\mathrm{EGFP}^{+}$interneuron (top panel; top trace) and its $\mathrm{NNG}^{+}$cell (top panel; bottom trace) in the presence of $1 \mu \mathrm{m}$ TTX. By applying $0.3 \mathrm{~nm}$ latrotoxin for $5 \mathrm{~min}$ and then switching to a $0.5 \mathrm{~mm}$ $\mathrm{Ca}^{2+}$ solution, we were able to induce bursts of mEPSCs both in the interneuron (b1) (bottom panel; top trace) and in its sNG2 ${ }^{+}$cell (b2) (bottom panel; bottom trace). $\boldsymbol{B}$, Cross-correlation histogram shows the absence of nonrandom synchronized mEPSCs in closely associated pairs of $\mathrm{EGFP}^{+}$interneurons and sNG2 ${ }^{+}$cells. The histogram shows data pooled from eight NG2 ${ }^{+}$ cell-interneuron pairs. All recordings were performed in the presence of $100 \mu \mathrm{m}$ picrotoxin using a cesium-methanesulfonate internal solution.

However, $\mathrm{NG}^{+}{ }^{+}$cells across various white and gray matter regions differ in cell morphology (Dawson et al., 2003), physiological properties (Chittajallu et al., 2004), and patterns of gene expression (Gensert and Goldman, 2001). Moreover, distinct $\mathrm{NG}_{2}{ }^{+}$cell subpopulations differ in terms of cellular fate. Whereas NG2 ${ }^{+}$cells generate oligodendrocytes in white matter (Polito and Reynolds, 2005), the majority in gray matter regions will remain quiescent, or have the potential to give rise to interneurons in the hippocampus (Belachew et al., 2003; Aguirre et al.,
2004) and in the adult cortex (Dayer et al., 2005). Therefore, synaptic integration appears to be a general feature of $\mathrm{NG}^{+}$ cells, independent of their physiological properties or their cell fate.

Our data show that hilar $\mathrm{sNG} 2^{+}$cells are synaptically integrated in such a way that their activity reflects that of local neurons. Indeed, we observed very distinctive patterns of activity under basal unstimulated conditions, during picrotoxin-induced epileptic-like activity, and during carbachol-induced gamma oscillations. Therefore, even if most $\mathrm{NG}^{+}$cells are contacted by glutamatergic synapses, their pattern of activity will mostly depend on the activity of the local network. It could be hypothesized that this activity may inform $\mathrm{NG} 2{ }^{+}$cells on their precise location in the brain, or the degree of maturity of the surrounding synaptic network and its current state of activity (oscillations, epileptic activity, etc.). Thus, such differences should be taken into account when analyzing the influence of glutamatergic activity on $\mathrm{NG} 2{ }^{+}$cells in distinct brain regions.

Hilar $\mathrm{sNG}^{+}$cells and inhibitory interneurons can be contacted by the same neurons and exhibit similar patterns of activity

The present study shows that hilar sNG2 ${ }^{+}$cells and interneurons receive inputs from the same neuronal population (i.e., dentate gyrus granule cells and CA3 pyramidal neurons). Through this shared connectivity, $\mathrm{sNG} 2{ }^{+}$cells partially reflect the activity arising in adjacent interneurons. However, glutamatergic activity in sNG2 ${ }^{+}$cells represents only a small fraction of the activity observed in interneurons. For example, the amplitudes of the recurrent glutamatergic activity during a CA3 burst are on average 15 -fold smaller in $\mathrm{sNG} 2{ }^{+}$cells than in their associated interneurons. Therefore, even large CA3 bursts induce only small depolarizing potentials $(\sim 5 \mathrm{mV})$ in $\mathrm{sNG} 2{ }^{+}$cells, supporting the hypothesis that glutamatergic inputs might influence $\mathrm{sNG}{ }^{+}$cells through mechanisms other than simple membrane depolarization (Lin et al., 2005). For example, it has been shown that glutamatergic inputs induce calcium entry into hippocampal NG2 ${ }^{+}$ cells via $\mathrm{Ca}^{2+}$-permeable AMPARs (Bergles et al., 2000; Lin et al., 2005; Ge et al., 2006). To confirm the presence of $\mathrm{Ca}^{2+}$ permeable AMPARs in hilar sNG2 ${ }^{+}$cells, we analyzed the current-voltage relationship of responses evoked in $\mathrm{sNG} 2^{+}$cells by electrical stimulation of the granule cell and CA3 pyramidal cell layers. In the presence of $30 \mu \mathrm{M}$ intracellular spermine, we observed a slightly rectifying $I-V$ relationship, indicating the presence of a similar proportion of $\mathrm{Ca}^{2+}$-permeable AMPARs in synapses formed by mossy fibers and CA3 recurrent fibers (supplemental Fig. 6, available at www.jneurosci.org as supplemental material).

The present study provides evidence that closely associated hilar $\mathrm{sNG} 2^{+}$cells and interneurons are frequently connected to the same presynaptic neurons. However, we never observed any synchronized events when we recorded mEPSC activity from hilar sNG2 ${ }^{+}$cells and their associated interneurons, even in the presence of latrotoxin, demonstrating that synchronized sEPSCs are elicited by glutamate release from distinct active zones. These results agree with electron-microscopic observations showing that a single presynaptic bouton in the hippocampus can contact both an $\mathrm{NG}^{+}$cell and a neuron via two distinct active zones (Bergles et al., 2000).

More importantly, the degree of synchronization of $\mathrm{sNG} 2^{+}$ cells and interneurons is dependent on their relative distance. These shared connections are likely to allow sNG2 ${ }^{+}$cells to react 
to changes in activity arising specifically in their associated interneurons.

\section{Does glutamatergic activity in $\mathrm{sNG}^{+}{ }^{+}$cells influence their fate?}

Recent studies have shown that $\mathrm{sNG}^{+}$cells purified from early postnatal brain can give rise to neurons in vitro (Kondo and Raff, 2000; Belachew et al., 2003) and in vivo (Shihabuddin et al., 2000; Aguirre et al., 2004; Dayer et al., 2005). It has been suggested that $\mathrm{NG} 2{ }^{+}$cells give rise to specific subtypes of interneurons in the postnatal hippocampus (Belachew et al., 2003; Aguirre et al., 2004) and olfactory bulb (Aguirre and Gallo, 2004), and in the adult cortex (Dayer et al., 2005). Approximately 30\% of cortical $\mathrm{NG}_{2}{ }^{+}$cells are able to elicit TTX-sensitive spikes, and $10 \%$ express the immature neuronal markers TuJ1 and HuC/D (Chittajallu et al., 2004). We also observed that a significant fraction of hippocampal sNG2 ${ }^{+}$cells elicits TTX-sensitive single spikes in response to depolarization (J.-M. Mangin, A. Kunze, and V. Gallo, unpublished data). Repetitive firing of action potentials have even been recently reported in synaptically connected $\mathrm{NG}_{2}{ }^{+}$cells recorded from the rat cerebellar white matter (Káradóttir et al., 2008). Therefore, a fraction of the synaptically connected sNG2 ${ }^{+}$cells might represent "prewired" neuronal precursors that, under appropriate conditions, could differentiate into inhibitory interneurons.

We observed that the percentage of total hilar $\mathrm{sNG}{ }^{+}$cells that are spiking tends to decrease during the second postnatal week, whereas the density of their synaptic inputs increases. A similar negative correlation between spiking properties and synaptic activity has been reported in the cortex during this developmental time period (Chittajallu et al., 2004). Furthermore, synaptically active $\mathrm{NG}^{+}$cells tend to exhibit a hyperpolarized resting membrane potential $(-84 \pm 8 \mathrm{mV} ; n=42)$ and a low membrane resistance $(290 \pm 230 \mathrm{M} \Omega)$, suggesting that most of these cells are not immediately destined for a neuronal fate. This discrepancy might be explained by our previous observation that $\mathrm{NG} 2{ }^{+}$cells downregulate EGFP and NG2 expression as they differentiate into interneurons (Belachew et al., 2003). Therefore, we may have excluded NG2 ${ }^{+}$cells that exhibit more mature neuronal properties by limiting our recordings to cells expressing higher levels of EGFP and NG2.

\section{Conclusion and implications}

Our study demonstrates by paired recording analysis that a population of hippocampal NG2 ${ }^{+}$progenitors is integrated into the local neuronal network and can respond to different patterns of neuronal activity. Based on their similar network integration, hippocampal sNG2 ${ }^{+}$cells and inhibitory interneurons receive information about the excitation level of the local circuit with comparable spatiotemporal patterns. Several studies have shown that interneurons in the hilar region play a key role in regulating the local network activity by forming feedforward and feedbackward circuits (Scharfman, 1994a; Freund and Buzsáki, 1996). Hence, the loss of hilar interneurons has been associated with distinct epileptic disorders and directly linked to local hyperexcitability (Obenaus et al., 1993; Houser and Esclapez, 1996; Buckmaster and Jongen-Relo, 1999; Ratzliff et al., 2004). It could be speculated that, under pathological conditions that cause local hyperexcitability, synaptically connected $\mathrm{sNG} 2{ }^{+}$cells ensure appropriate network function. This might occur either by modulating neuronal activity or by generating new interneurons to optimize local inhibition. Future studies will investigate the role of functional integration of $\mathrm{sNG} 2^{+}$cells into the neuronal network in CNS pathology and repair.

\section{References}

Aguirre A, Gallo V (2004) Postnatal neurogenesis and gliogenesis in the olfactory bulb from NG2-expressing progenitors of the subventricular zone. J Neurosci 24:10530-10541.

Aguirre AA, Chittajallu R, Belachew S, Gallo V (2004) NG2-expressing cells in the subventricular zone are type C-like cells and contribute to interneuron generation in the postnatal hippocampus. J Cell Biol 165:575-589.

Auger C, Marty A (1997) Heterogeneity of functional synaptic parameters among single release sites. Neuron 19:139-150.

Avoli M, Barbarosie M, Lücke A, Nagao T, Lopantsev V, Köhling R (1996) Synchronous GABA-mediated potentials and epileptiform discharges in the rat limbic system in vitro. J Neurosci 16:3912-3924.

Belachew S, Aguirre AA, Wang H, Vautier F, Yuan X, Anderson S, Kirby M, Gallo V (2002) Cyclin-dependent kinase-2 controls oligodendrocyte progenitor cell cycle progression and is downregulated in adult oligodendrocyte progenitors. J Neurosci 22:8553-8562.

Belachew S, Chittajallu R, Aguirre AA, Yuan X, Kirby M, Anderson S, Gallo V (2003) Postnatal NG2 proteoglycan-expressing progenitor cells are intrinsically multipotent and generate functional neurons. J Cell Biol 161:169-186

Bergles DE (2005) Shape-shifting at a cerebellar synapse allows submillisecond signaling. Nat Neurosci 8:1279-1281.

Bergles DE, Jahr CE (1997) Synaptic activation of glutamate transporters in hippocampal astrocytes. Neuron 19:1297-1308.

Bergles DE, Roberts JD, Somogyi P, Jahr CE (2000) Glutamatergic synapses on oligodendrocyte precursor cells in the hippocampus. Nature 405:187-191.

Buckmaster PS, Jongen-Rêlo AL (1999) Highly specific neuron loss preserves lateral inhibitory circuits in the dentate gyrus of kainate-induced epileptic rats. J Neurosci 19:9519-9529.

Butt AM, Hamilton N, Hubbard P, Pugh M, Ibrahim M (2005) Synantocytes: the fifth element. J Anat 207:695-706.

Chittajallu R, Aguirre A, Gallo V (2004) NG2-positive cells in the mouse white and grey matter display distinct physiological properties. J Physiol 561:109-122.

Chittajallu R, Aguirre AA, Gallo V (2005) Downregulation of plateletderived growth factor-alpha receptor-mediated tyrosine kinase activity as a cellular mechanism for $\mathrm{K}^{+}$-channel regulation during oligodendrocyte development in situ. J Neurosci 25:8601-8610.

Chittajallu R, Kunze A, Mangin JM, Gallo V (2007) Differential synaptic integration of interneurons in the outer and inner molecular layers of the developing dentate gyrus. J Neurosci 27:8219-8225.

Cohen I, Huberfeld G, Miles R (2006) Emergence of disinhibition-induced synchrony in the CA3 region of the guinea pig hippocampus in vitro. J Physiol 570:583-594.

Dawson MR, Polito A, Levine JM, Reynolds R (2003) NG2-expressing glial progenitor cells: an abundant and widespread population of cycling cells in the adult rat CNS. Mol Cell Neurosci 24:476-488.

Dayer AG, Cleaver KM, Abouantoun T, Cameron HA (2005) New GABAergic interneurons in the adult neocortex and striatum are generated from different precursors. J Cell Biol 168:415-427.

Fischer Y (2004) The hippocampal intrinsic network oscillator. J Physiol 554:156-174.

Freund TF, Buzsáki G (1996) Interneurons of the hippocampus. Hippocampus 6:347-470.

Gallo V, Zhou JM, McBain CJ, Wright P, Knutson PL, Armstrong RC (1996) Oligodendrocyte progenitor cell proliferation and lineage progression are regulated by glutamate receptor-mediated $\mathrm{K}^{+}$channel block. J Neurosci 16:2659-2670.

Ge WP, Yang XJ, Zhang Z, Wang HK, Shen W, Deng QD, Duan S (2006) Long-term potentiation of neuron-glia synapses mediated by $\mathrm{Ca}^{2+}$ permeable AMPA receptors. Science 312:1533-1537.

Gensert JM, Goldman JE (2001) Heterogeneity of cycling glial progenitors in the adult mammalian cortex and white matter. J Neurobiol 48:75-86.

Houser CR, Esclapez M (1996) Vulnerability and plasticity of the GABA system in the pilocarpine model of spontaneous recurrent seizures. Epilepsy Res 26:207-218.

Jabs R, Pivneva T, Hüttmann K, Wyczynski A, Nolte C, Kettenmann H, 
Steinhäuser C (2005) Synaptic transmission onto hippocampal glial cells with hGFAP promoter activity. J Cell Sci 118:3791-3803.

Káradóttir R, Hamilton NB, Bakiri Y, Attwell D (2008) Spiking and nonspiking classes of oligodendrocyte precursor glia in CNS white matter. Nat Neurosci 1:450-456.

Kondo T, Raff M (2000) Oligodendrocyte precursor cells reprogrammed to become multipotential CNS stem cells. Science 289:1754-1757.

Kukley M, Capetillo-Zarate E, Dietrich D (2007) Vesicular glutamate release from axons in white matter. Nat Neurosci 10:311-320.

Kukley M, Kiladze M, Tognatta R, Hans M, Swandulla D, Schramm J, Dietrich D (2008) Glial cells are born with synapses. FASEB J, in press.

Lin SC, Huck JH, Roberts JD, Macklin WB, Somogyi P, Bergles DE (2005) Climbing fiber innervation of NG2-expressing glia in the mammalian cerebellum. Neuron 46:773-785.

Miles R, Wong RK (1987) Inhibitory control of local excitatory circuits in the guinea-pig hippocampus. J Physiol 388:611-629.

Obenaus A, Esclapez M, Houser CR (1993) Loss of glutamate decarboxylase mRNA-containing neurons in the rat dentate gyrus following pilocarpine-induced seizures. J Neurosci 13:4470-4485.

Paukert M, Bergles DE (2006) Synaptic communication between neurons and NG2+ cells. Curr Opin Neurobiol 16:515-521.

Polito A, Reynolds R (2005) NG2-expressing cells as oligodendrocyte progenitors in the normal and demyelinated adult central nervous system. J Anat 207:707-716.

Ratzliff AH, Howard AL, Santhakumar V, Osapay I, Soltesz I (2004) Rapid deletion of mossy cells does not result in a hyperexcitable dentate gyrus: implications for epileptogenesis. J Neurosci 24:2259-2269.

Rigo JM, Badiu CI, Legendre P (2003) Heterogeneity of postsynaptic receptor occupancy fluctuations among glycinergic inhibitory synapses in the zebrafish hindbrain. J Physiol 553:819-832.

Salin PA, Scanziani M, Malenka RC, Nicoll RA (1996) Distinct short-term plasticity at two excitatory synapses in the hippocampus. Proc Natl Acad Sci U S A 93:13304-13309.

Scharfman HE (1994a) Synchronization of area CA3 hippocampal pyramidal cells and non-granule cells of the dentate gyrus in bicuculline-treated rat hippocampal slices. Neuroscience 59:245-257.

Scharfman HE (1994b) Evidence from simultaneous intracellular recordings in rat hippocampal slices that area CA3 pyramidal cells innervate dentate hilar mossy cells. J Neurophysiol 72:2167-2180.

Scharfman HE (2007) The CA3 "backprojection" to the dentate gyrus. Prog Brain Res 163:627-637.

Shigemoto R, Kinoshita A, Wada E, Nomura S, Ohishi H, Takada M, Flor PJ, Neki A, Abe T, Nakanishi S, Mizuno N (1997) Differential presynaptic localization of metabotropic glutamate receptor subtypes in the rat hippocampus. J Neurosci 17:7503-7522.

Shihabuddin LS, Horner PJ, Ray J, Gage FH (2000) Adult spinal cord stem cells generate neurons after transplantation in the adult dentate gyrus. J Neurosci 20:8727-8735.

Takahashi T (2005) Postsynaptic receptor mechanisms underlying developmental speeding of synaptic transmission. Neurosci Res 53:229-240.

Toth K, Suares G, Lawrence JJ, Philips-Tansey E, McBain CJ (2000) Differential mechanisms of transmission at three types of mossy fiber synapse. J Neurosci 20:8279-8289.

Yuan X, Eisen AM, McBain CJ, Gallo V (1998) A role for glutamate and its receptors in the regulation of oligodendrocyte development in cerebellar tissue slices. Development 125:2901-2914.

Yuan X, Chittajallu R, Belachew S, Anderson S, McBain CJ, Gallo V (2002) Expression of the green fluorescent protein in the oligodendrocyte lineage: a transgenic mouse for developmental and physiological studies. J Neurosci Res 70:529-545.

Ziskin JL, Nishiyama A, Rubio M, Fukaya M, Bergles DE (2007) Vesicular release of glutamate from unmyelinated axons in white matter. Nat Neurosci 10:321-330. 